\title{
Myocilin Is Involved in NgR1/Lingo-1-Mediated Oligodendrocyte Differentiation and Myelination of the Optic Nerve
}

\author{
Heung Sun Kwon, ${ }^{1}$ Naoki Nakaya, ${ }^{1}$ Mones Abu-Asab, ${ }^{2}$ Hong Sug Kim, ${ }^{3}$ and Stanislav I. Tomarev ${ }^{1}$ \\ ${ }^{1}$ Retinal Ganglion Cell Biology Section, Laboratory of Retinal Cell and Molecular Biology and ${ }^{2} H i s t o l o g y$ Core, National Eye Institute, National Institutes of \\ Health (NIH), Bethesda, Maryland 20892, and ${ }^{3}$ Neuro-Oncology Branch, National Cancer Institute, NIH, Bethesda, Maryland 20892
}

\begin{abstract}
Myocilin is a secreted glycoprotein that belongs to a family of olfactomedin domain-containing proteins. Although myocilin is detected in several ocular and nonocular tissues, the only reported human pathology related to mutations in the MYOCILIN gene is primary open-angle glaucoma. Functions of myocilin are poorly understood. Here we demonstrate that myocilin is a mediator of oligodendrocyte differentiation and is involved in the myelination of the optic nerve in mice. Myocilin is expressed and secreted by optic nerve astrocytes. Differentiation of optic nerve oligodendrocytes is delayed in Myocilin-null mice. Optic nerves of Myocilin-null mice contain reduced levels of several myelin-associated proteins including myelin basic protein, myelin proteolipid protein, and $2^{\prime} 3^{\prime}$-cyclic nucleotide $3^{\prime}$ phosphodiesterase compared with those of wild-type littermates. This leads to reduced myelin sheath thickness of optic nerve axons in Myocilin-null mice compared with wild-type littermates, and this difference is more pronounced at early postnatal stages compared with adult mice. Myocilin also affects differentiation of oligodendrocyte precursors in vitro. Its addition to primary cultures of differentiating oligodendrocyte precursors increases levels of tested markers of oligodendrocyte differentiation and stimulates elongation of oligodendrocyte processes. Myocilin stimulation of oligodendrocyte differentiation occurs through the NgR1/Lingo-1 receptor complex. Myocilin physically interacts with Lingo-1 and may be considered as a Lingo-1 ligand. Myocilin-induced elongation of oligodendrocyte processes may be mediated by activation of FYN and suppression of RhoA GTPase.
\end{abstract}

Key words: astrocyte; differentiation; Lingo-1; myelin; myocilin; oligodendrocyte

\section{Introduction}

MYOCILIN (MYOC) was the first gene in which identified mutations were found to cause glaucoma, the second leading cause of blindness in the world (Adam et al., 1997, Stone et al., 1997). $M Y O C$ encodes a secreted glycoprotein and is expressed in ocular and several nonocular tissues. In the eye, MYOC expression has been detected in the tissues responsible for aqueous humor production (ciliary body) and outflow (trabecular meshwork), as well as in the iris, sclera, retinal pigmented epithelium, and optic nerve (Adam et al., 1997, Ortego et al., 1997, Stone et al., 1997, Tomarev et al., 2003). Available data suggest that expression of mutated myocilin in the trabecular meshwork leads to the activation of an unfolded protein response (Joe et al., 2003, Joe and Tomarev, 2010, Zode et al., 2011) and increases sensitivity of cells to oxidative stress (Joe and Tomarev, 2010). This may lead to

Received Nov. 7, 2013; revised Jan. 24, 2014; accepted March 11, 2014.

Author contributions: H.S. Kwon designed research; H.S. Kwon, N.N., and M.A.-A. performed research; H.S. Kim contributed unpublished reagents/analytic tools; H.S. Kwon analyzed data; H.S. Kwon and S.I.T. wrote the paper.

This work was supported by the Intramural Research Programs of the National Eye Institute, National Institutes of Health. We thank Drs. Haohua Qian for help with flash visual evoked potentials recording and Thomas V. Johnson for critical reading of this manuscript.

The authors declare no competing financial interests.

Correspondence should be addressed to Stanislav I. Tomarev, Building 6, Room 212, 6 Center Drive, National Eye Institute, NIH, Bethesda, MD 20892. E-mail: tomarevs@nei.nih.gov.

DOI:10.1523/JNEUROSCI.4731-13.2014

Copyright $\odot 2014$ the authors $\quad 0270-6474 / 14 / 345539-13 \$ 15.00 / 0$ deterioration of trabecular meshwork function and elevation of intraocular pressure. The pathological role of mutated myocilin in other ocular and nonocular tissues is less clear. Myoc-null mice do not show any detectable changes in intraocular pressure or defects in the optic nerve head (Kim et al., 2001). However, Myocnull mice exhibit reduced cortical bone thickness (Kwon et al., 2013b), a moderate reduction in the amount of dystrophinassociated syntrophin in the skeletal muscle (Joe et al., 2012), and defects in sciatic nerve myelination (Kwon et al., 2013a) as compared with wild-type littermates. In the sciatic nerve, myocilin is expressed in Schwann cells (Ohlmann et al., 2003) and localized to the nodes of Ranvier where it interacts with gliomedin, neurofascin, and NrCAM, proteins essential for node formation and function (Eshed et al., 2005, Kwon et al., 2013a). Sciatic nerves of Myoc-null mice have thinner myelin sheaths and partial disorganization of Ranvier nodes when compared with wild-type littermates (Kwon et al., 2013a).

In the CNS, including the optic nerve, oligodendrocytes play a critical role in the myelination of axons. Several regulators that negatively or positively regulate myelination in the CNS have been identified (Emery, 2010). One of the negative regulators of myelination is leucine-rich repeat and Ig domain-containing 1 (Lingo-1), a transmembrane signaling protein expressed in both oligodendrocytes and neurons, but not in astrocytes (Mi et al., 2005). In neurons, Lingo-1 is a coreceptor of the Nogo receptor 
complex that may mediate the inhibition of axon growth (Mi et al., 2004). We have recently shown that olfactomedin 1 (Olfm1), a protein belonging to the same superfamily as myocilin, interacts with the Nogo receptor complex preferentially binding NgR1. Olfm 1 caused the inhibition of NgR1 signaling by interfering with interaction between NgR1 and its coreceptors, p75NTR or LINGO-1 (Nakaya et al., 2012).

In the present communication, we investigated a role of myocilin in the optic nerve. Myoc-null mice show defects in optic nerve myelination. We demonstrate that myocilin is expressed in astrocytes and plays a role in differentiation of oligodendrocytes acting through the Lingo-1/NgR1 complex.

\section{Materials and Methods}

Animals, plasmids, and antibodies. Mice were maintained in accordance with guidelines set forth by the National Eye Institute Committee on the Use and Care of Animals. Myoc-null mice (B6/129 mixed genetic background) have been described previously (Kim et al., 2001). Mice of either sex were used in experiments. Human FLAG- and alkaline phosphatase (AP)-tagged myocilin, myocilin- $\Delta \mathrm{C}$, and myocilin- $\Delta \mathrm{N}$ constructs have been described (Kwon et al., 2009). Antibodies were obtained from following sources: HSC70 (Santa Cruz Biotechnology); MBP and Lingo-1 (Abcam); neurofilament H, MBP, RhoA, Olig2, A2B5, and O4 (Millipore); Nogo, phosphor-Fyn, ErbB2, and ErbB3 (Cell Signaling Technology). Anti-mouse or rabbit IgG antibody conjugated to horseradish peroxidase were from GE. Alexa 488- or Alexa 594-conjugated antimouse, anti-rabbit, or anti-goat IgG was from Life Technologies. Antibodies against mouse myocilin were described previously (Malyukova et al., 2006). The human Lingo-1 extracellular domain sequence corresponding to residues 1-532 in the amino acid sequence of Lingo-1 was amplified by PCR using pCMV-Lingo-1 (Thermo Scientific) as a template. Oligonucleotide primers 5'-CACAAGCTTATGCAGGTGAGCA AGAGG-3' and 5'-CACGGATTCCTCGCCCGGCTGGTTGGAGAT-3' were used for amplification. The amplified fragment was cloned into the pCMV14-FLAG vector, FLAG-tagged protein was expressed in CHO cells, and purified using Anti-FLAG affinity gel (Sigma).

Quantitative PCR. Total RNA was isolated from oligodendrocytes using RNeasy mini-kit following manufacturer's instructions (Qiagen). cDNA was synthesized using $1 \mu \mathrm{g}$ of RNA as a template and SuperScript One-Step-RT-PCR System kit (Life Technologies) according to the manufacturer's instructions (Life Technologies). cDNA was diluted (1:20) and the quantitative PCRs (qPCRs) were performed on an ABI7900 sequence detection system (Applied Biosystems). Primers for qPCR were as follows: Mbp, 5'-CCCGTGGAGCCGTGATC-3' and 5' -TCTTCAAA CGAAAAGGGA-3'; Mog, 5'-ATGAAGGAGGCTACACCTGC-3' and 5'-CAAGTGCGATGAGAGTCAGC-3'; Mag, 5'-AACCAGTATGGC CAGAGAGC-3' and 5'-GTTCCGGGTTGGATTTTACC-3'; Gapdh, 5'CCCATCACCATCTTCCAGGAGCG-3' and $5^{\prime}$-CGGGAAGCTCACTG GCATGGCCT-3'. Gapdh was used for normalization. To quantifying the relative changes in gene expression, we used the $2^{-\Delta \Delta C}$ method. The average $C_{T}$ was calculated for the target genes and internal control (Gapdh) and the $\Delta \mathrm{C}_{\mathrm{T}}\left(\mathrm{C}_{\mathrm{T}, \text { target }}-\mathrm{C}_{\mathrm{T}, \mathrm{GAPDH}}\right)$ values were determined. All reactions were performed in triplicate using three independent samples.

Dorsal root ganglia cultures. Dissociated mouse dorsal root ganglia (DRG) cultures were grown in Neurobasal medium (Life Technologies) supplemented with B27 (Life Technologies) as described previously (Poliak et al., 2003, Eshed et al., 2005). Briefly, DRG of postnatal day 5 (P5) mice were trypsinized, seeded on poly-D-lysine/laminin 2-well culture slides (BD Bioscience) or poly-D-lysine-coated $13 \mathrm{~mm}$ slides (Sigma), and grown in Neurobasal medium, insulin, transferrin, and sodium selenite supplement, $0.2 \%$ BSA, $4 \mathrm{mg} / \mathrm{ml}$ D-glucose (Sigma), GlutaMAX (Life Technologies), $50 \mathrm{ng} / \mathrm{ml}$ NGF (Sigma), and antibiotics.

Immunoprecipitation and Western blots. Protein samples from tissues or cells were dissolved with RIPA lysis buffer (Sigma) containing $10 \mathrm{~mm}$ DTT and protease inhibitor (Sigma). After sonication for $30 \mathrm{~s}$ three times, the samples were denatured at $100^{\circ} \mathrm{C}$ for $5 \mathrm{~min}$. The denatured samples were analyzed using a $4-12 \%$ polyacrylamide Bis-Tris gel (Life Technologies). After electrophoresis, the proteins were transferred to a
PVDF membrane (Life Technologies). The membrane was blocked with $5 \%$ skim milk in Tris-buffered saline. Primary and secondary antibodies and SuperSignal West Dura Chemiluminescent Substrate (Thermo Fisher Scientific) were used to detect proteins. All Western blotting experiments were repeated at least three times.

Primary astrocyte and oligodendrocyte cultures. Mouse optic nerve astrocytes were derived from the anterior portions of C57BL/6 mouse optic nerves. The posterior pole of the eye was dissected, and the optic nerve head was freed from sclera and other neighboring tissues. The optic nerve head was sliced sagittally and the anterior portion of the optic nerve was carefully dissected from the prelaminar and postlaminar regions under a dissection microscope. Two or three explants of the anterior region were obtained from each eye. The explants were put into $\mathrm{T}-25 \mathrm{~cm}^{2}$ plastic tissue culture flasks, which had been conditioned with DMEM/F-12 supplemented with $10 \%$ FBS. The first passage cells were characterized by immunostaining with antibodies against GFAP and Olig2 to identify astrocytes and oligodendrocytes, respectively. Astrocytes were selected from primary cultures by growing cells for 1 week in modified astrocytedefined, serum-free medium (ADM; Clonetics) containing forskolin to suppress fibroblast growth. More than $95 \%$ of cells in second-passage cultures were positive for GFAP. They were grown to $60-80 \%$ confluency and starved in serum-free medium for 1 week before being used for experiments.

Immature oligodendrocytes were isolated using the MACS procedure following the manufacturer's instructions (Miltenyi Biotec). Optic nerve and brain tissues were collected from two to three P5-P7 mice for each isolation. For oligodendrocyte selection, cells were incubated with anti-O4 monoclonal antibodies magnetic beads in MACS BSA buffer (Miltenyi Biotec) for $15 \mathrm{~min}$ at $4^{\circ} \mathrm{C}$. Cells were applied to type MS Mini MACS columns in the presence of a strong magnetic field as recommended by the manufacturer. Columns were washed four times with staining buffer, followed by elution with MACS buffer in the absence of magnetic field. A plunger was applied for elution. The purity of isolated cells was assessed by immunostaining with $\mathrm{O} 4$ antibodies.

Immunohistochemistry. Frozen sections and free-floating sections were stained as previously described (Kwon et al., 2013a) with slight modifications. Tissues were permeabilized in $0.3 \%$ Triton X-100 (Sigma) in PBS for $30 \mathrm{~min}$, washed in PBS, then blocked in 4\% normal serum in PBS for $20 \mathrm{~min}$, and incubated with primary antibodies in $2 \%$ normal serum at $4^{\circ} \mathrm{C}$ overnight. The sections were washed with $0.3 \%$ Triton X-100 in PBS and then incubated with secondary antibodies raised in goat and conjugated to Alexa 488 or 594 for $1 \mathrm{~h}$ at room temperature (RT). Nuclei were counterstained with $0.5 \mu \mathrm{g} / \mathrm{ml}$ DAPI and mounted in Vectashield (Vector Laboratories). Staining without primary antibodies was used as a negative control.

Coimmunoprecipitation. Optic nerve lysates were cleared by centrifugation at $16,000 \times g$ for $15 \mathrm{~min}$, immunoprecipitated with antibodies against myocilin or Lingo- 1 at $4^{\circ} \mathrm{C}$ overnight, and then incubated with protein-A agarose (Roche) at RT for $1 \mathrm{~h}$. Bound proteins were eluted from agarose beads by boiling in SDS-PAGE sample buffer and analyzed by Western blotting using indicated antibodies. HEK-293 cells were transiently transfected with Lingo-1 and NgR1 using Lipofectamine 2000 (Life Technologies) and seeded in 6-well culture dishes. Cells were washed with PBS and lysed in lysis buffer $48 \mathrm{~h}$ after transfection. Cleared lysates were subjected to immunoprecipitation with Lingo-1 antibodies and then incubated with Protein-G magnetic beads (Life Technologies). Immunoprecipitates were analyzed by Western blotting using indicated antibodies.

RhoA assay. GST-Rhotekin binding domain and GST-PAK binding domain were obtained from Millipore. Small GTPase activities were measured as described previously (Ren et al., 1999). Briefly, progenitor and differentiated oligodendrocytes were lysed in $300 \mu \mathrm{l}$ of $25 \mathrm{~mm}$ HEPES, pH 7.5, containing 1\% Igepal CA-630, $150 \mathrm{~mm} \mathrm{NaCl}, 10 \mathrm{~mm}$ $\mathrm{MgCl}_{2}, 1 \mathrm{~mm}$ EDTA, and $1 \%$ glycerol. Cell lysates $(200-500 \mu \mathrm{g})$ were clarified at $100,000 \times g$ for $15 \mathrm{~min}$ and incubated for 40 min with $20 \mu \mathrm{g}$ of GST fusion proteins containing the Rhotekin binding domain (for RhoA assay) bound to glutathione-Sepharose beads (Millipore). Samples were washed with lysis buffer and then immunoblotted with anti-RhoA.

AP binding assay. AP-tagged fusion protein expression constructs were transfected into HEK-293 cells to generate conditioned medium (CM) 
containing AP-fusion proteins. The culture medium was changed to the fresh serum-free medium $24 \mathrm{~h}$ after transfection, CM was harvested $24-48 \mathrm{~h}$ later, filtered through a $0.22 \mu \mathrm{m}$ filter, and stored at $-80^{\circ} \mathrm{C}$ until use. Absolute concentration and integrity of AP-tagged myocilin was determined by Western blotting using samples with a known amount of purified myocilin. COS-7 cells were transfected with Lingo-1, NgR1, or vector plasmids and incubated with AP-myocilin containing CM for 90 min at RT $48 \mathrm{~h}$ after transfection. Cells were washed five times, fixed by treatment with $60 \%$ acetone, $3 \%$ formaldehyde, and $20 \mathrm{~mm}$ HEPES, $\mathrm{pH}$ 7.5 , for $30 \mathrm{~s}$ and surface binding was visualized using nitro blue tetrazolium (NBT) and 5-bromo-4-chloro-3'-indolyphosphate (BCIP) as AP substrates following the manufacturer's instructions (GenHunter). The images of stained cells were obtained with a dissection microscope (Zeiss STEMI SV-11). For quantitative analysis of the activity of cell-bound AP, 1-Step PNPP (Pierce) was added to the fixed cells and the absorbance at $405 \mathrm{~nm}$ in the supernatant was measured using a microplate reader (BioRad Model-680).

Recording of flash visual evoked potentials. Flash visual evoked potentials (fVEPs) were recorded as described previously (Goto et al., 2001). Briefly, mice were kept in a dark room for 30 min and prepared under dim red illumination. Mice were anesthetized with an intraperitoneal injection of $5 \mu \mathrm{l} / \mathrm{g}$ body weight of ketamine $(20 \mathrm{mg} / \mathrm{ml})$ and xylazine $(2$ $\mathrm{mg} / \mathrm{ml}$ ) mixture. The pupil was dilated with $2.5 \%$ phenylephrine $\mathrm{HCl}$, and the animals were placed on a heating pad to maintain body temperature. fVEPs were recorded using a needle electrode placed on the scalp overlying the visual cortex. Similar needle electrodes inserted under the cheek and the back skin served as reference and ground leads, respectively. The luminance of the flash device was $200 \mathrm{~cd}-\mathrm{s} / \mathrm{m}^{2}$. Responses were amplified $1-1000 \mathrm{~Hz}$, and the responses to 100 successive flashes presented at a rate of $1 \mathrm{~Hz}$ were averaged in each mouse; the data were acquired using an Espion system (Diagnosys).

Electron microscopy. Mice were anesthetized using a lethal dose of ketamine/xylazine injected intraperitoneally. Anesthetized animals were perfused with a fixative containing $4 \%$ paraformaldehyde, $2.5 \%$ glutaraldehyde, $0.13 \mathrm{~N} \mathrm{NaH}_{4} \mathrm{PO}_{4}$, and $0.11 \mathrm{M} \mathrm{NaOH}, \mathrm{pH}$ 7.4. Perfused tissues were fixed in PBS-buffered 2.5\% glutaraldehyde and 0.5\% osmium tetroxide, dehydrated, and embedded into Spurr's epoxy resin. Ultrathin sections $(90 \mathrm{~nm})$ were made, double-stained with uranyl acetate and lead citrate, and viewed in a JEOL JEM 1010 transmission electron microscope equipped with digital imaging camera. The g-ratio was determined by dividing the circumference of an axon (without myelin) by the circumference of the same axon including myelin. Six wild-type and seven Myoc-null mice were analyzed.

Assessment of length of oligodendrocyte processes. Primary oligodendrocytes were grown for $8 \mathrm{~d}$ at $37^{\circ} \mathrm{C}$ in $5 \% \mathrm{CO}_{2}$, subsequently fixed in $4 \%$ paraformaldehyde in PBS for 10 min, washed twice with PBS, and stored in $0.05 \%$ sodium azide (Sigma) in PBS at $4^{\circ} \mathrm{C}$. Baseline media were supplemented with myocilin $(1 \mu \mathrm{g} / \mathrm{ml})$ when indicated to test its effect on oligodendrocyte process outgrowth. Oligodendrocyte process outgrowth per cell was assessed as follows. Given a directory containing pairs of images corresponding to nuclear (DAPI) and MBP images, the plugin opened the images in a nuclear and a neuronal stack. Images were first preprocessed to optimize uniformity of illumination and contrast in the input images. This step consisted of subtraction of a background image to reduce artifacts generated by the acquisition system as well as contrast enhancement, rolling ball radius background subtraction, despeckling, and a Gaussian blur by the commands built into ImageJ. These preprocessing steps were first performed on a small subset of images to allow choosing the threshold to be applied to the oligodendrocyte process outgrowth images. The outgrowth stack was then skeletonized and the portions of the skeleton corresponding to the cell body were removed by subtracting the oligodendrocyte nuclei stack. The total length of the processes was estimated by measuring the area covered by the skeleton in each image and oligodendrocyte nuclei were counted. The results table was saved to a text file and the oligodendrocyte nuclei and skeleton stacks as image stacks for later visual inspection.

Lentivirus production and infection. cDNA was inserted into Gateway entry vector pCR8/GW/TOPO and subsequently into pLenti4/TO/V5DEST. Lentivirus was produced in $293 \mathrm{FT}$ cells with a packaging mix

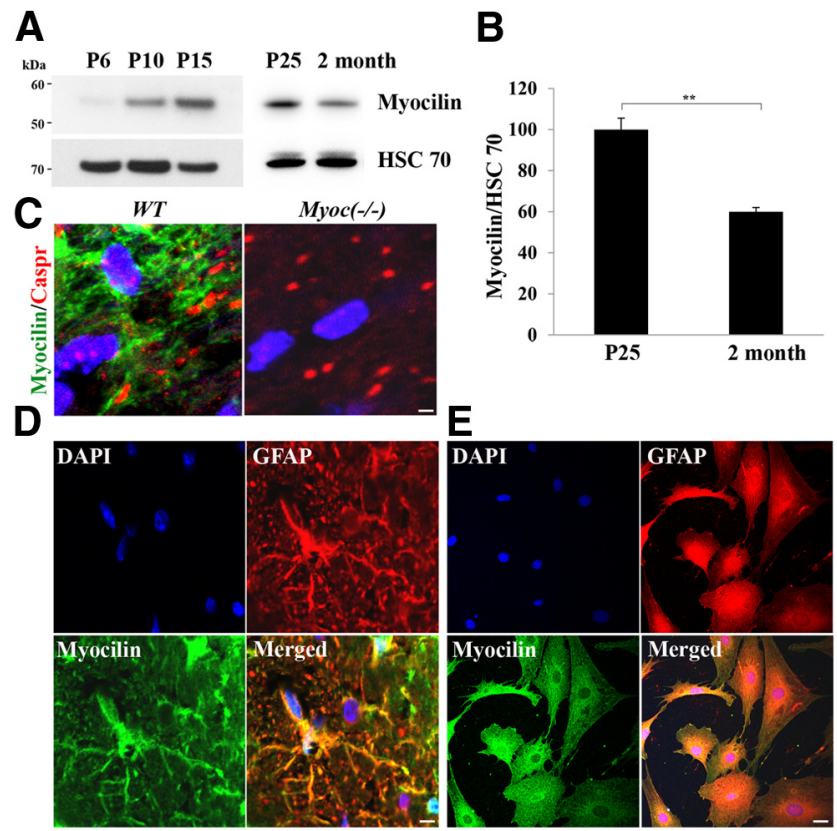

Figure 1. Myocilin expression in the mouse optic nerve. $\boldsymbol{A}$, Western blot analysis of myocilin expression in postnatal and adult optic nerves. Myocilin antiserum was used in 1:2000 dilution. Staining of the same blot with antibodies against HSC70 (1:5000 dilution) was used for normalization of loading. $\boldsymbol{B}$, Quantification of three independent Western blot experiments as in $\boldsymbol{A}$. The level of myocilin in P25 optic nerve was taken as $100 \%$ ( $\left.{ }^{* *} p<0.01\right)$. C, Confocal images of the optic nerve of 2-month-old wild-type (WT) and Myoc-null mice in longitudinal sections. Sections were stained with antibodies against myocilin (green; 1:500 dilution) and perinodal marker Caspr (red; 1:200 dilution). Nuclei were stained with DAPI (blue). D, Confocal images of the optic nerve of 1-month-old mice in longitudinal sections. Sections were stained with antibodies against myocilin (green; 1:500 dilution) and GFAP (red; 1:500 dilution). Nuclei were stained with DAPI (blue). $\boldsymbol{E}$, Confocal images of astrocytes isolated from P7 optic nerve and cultivated for $7 \mathrm{~d}$. Astrocytes were stained with antibodies against GFAP (red; 1:1000 dilution) and myocilin (green; 1: 600 dilution). Nuclei were stained with DAPI (blue).Scale bars: C, $2 \mu \mathrm{m}$; $D, E, 10 \mu \mathrm{m}$.

(ViraPower mix; Life Technologies). Plasmids were transfected with Lipofectamine and Plus reagent (Life Technologies). After $3 \mathrm{~h}$, media was changed with $5 \%$ FBS. Virus-laden supernatant was collected at $72 \mathrm{~h}$. The supernatant was filtered and concentrated by ultracentrifugation, and viral titer was determined by serial dilution. Mouse oligodendrocytes were plated into 2-well PDL-coated plates in SATO modified medium containing $5 \mathrm{mg} / \mathrm{ml}$ insulin, $50 \mathrm{mg} / \mathrm{ml}$ transferrin, 1.6

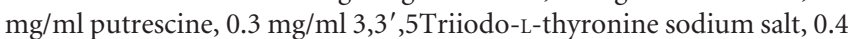
$\mathrm{mg} / \mathrm{ml}$ thyroxine, $10 \mathrm{ng} / \mathrm{ml}$ PDGF, and $10 \mathrm{ng} / \mathrm{ml} \mathrm{FGF}$ for $2 \mathrm{~d}$. The medium was replaced with SATO medium without PDGF, containing full-length LINGO-1 lentivirus, or control lentivirus at $5 \mathrm{MOI}$. Cells were incubated for $24 \mathrm{~h}$, virus-containing medium was removed, and cells were fed with medium containing 3,3',5-Triiodo-L-thyronine sodium salt, to induce differentiation.

Statistical analysis. Each experimental condition had between four and six explants per $n$, with a minimum of $n=3$ for each experimental condition. Outgrowth measurements for each experimental condition were pooled and averaged. Error bars are presented as mean \pm SEM. Two-tailed ANOVA was performed on the raw pooled data, and statistical significance was determined by a two-tailed Student's $t$ test or Bonferroni multiple comparisons post hoc test was used when comparison of three or more treatment groups was made (IBM SPSS Statistics 17).

\section{Results}

Myocilin is expressed in optic nerve astrocytes

It has been reported that myocilin is detected in the optic nerve of adult rats (Ohlmann et al., 2003), pigs (Noda et al., 2000), and humans (Karali et al., 2000, Clark et al., 2001, Ricard et al., 2001). 


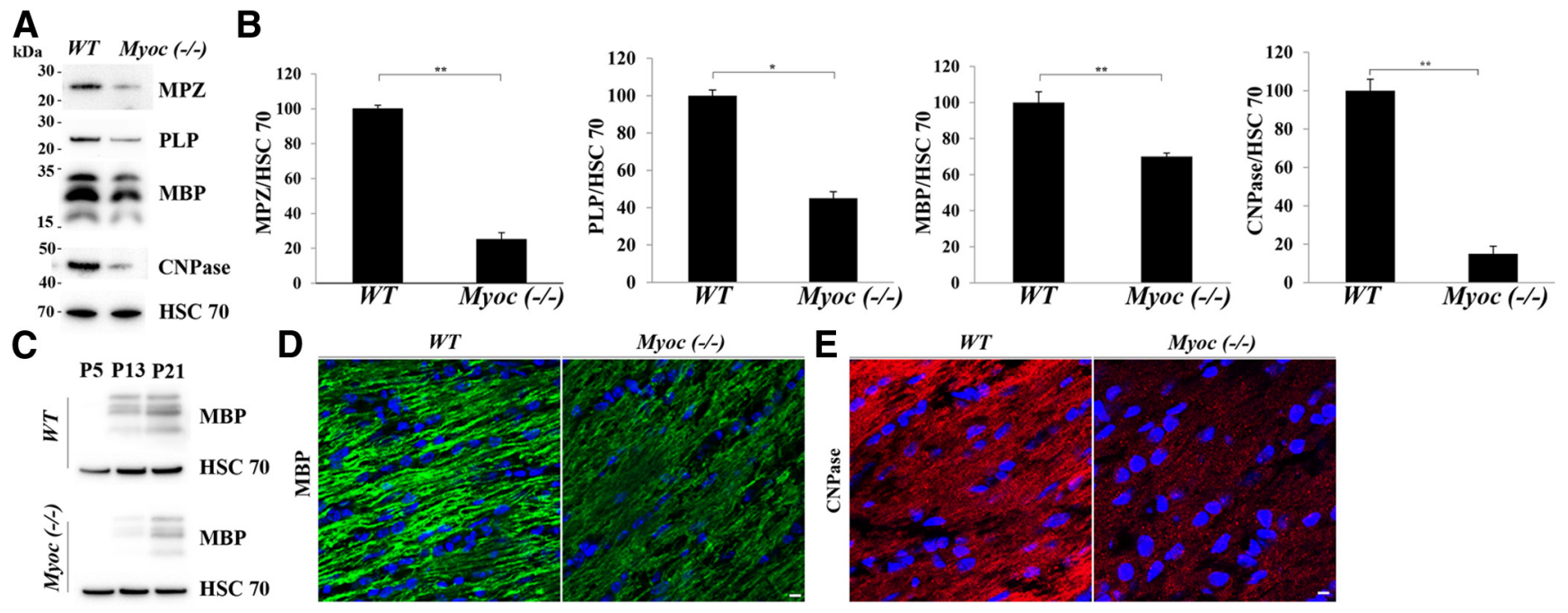

Figure 2. Reduced levels of myelin proteins in the optic nerve of Myoc-null mice and effects of myocilin on differentiation of oligodendrocyte precursors. $A$, Western blot analysis of optic nerve lysates of adult wild-type (WT) and Myoc-null mice using MBP (1:1000 dilution), PLP (1:1,000 dilution), CNPase (1:1000 dilution), and MPZ (1: 1000 dilution) antibodies. Staining of the same blots with antibodies against HSC70 (1:5000 dilution) was used for normalization of loading. $\boldsymbol{B}$, Quantification of three independent Western blot experiments as in $\boldsymbol{A}$. The levels of corresponding proteins in the optic nerve of wild-type mice were taken as $100 \%\left({ }^{*} p<0.05 ;{ }^{* *} p<0.01\right)$. C, MBP levels in the optic nerve lysates of wild-type and Myoc-null mice of different ages (P5-P21) as judged by Western blot analysis. Staining of the same blot with antibodies against HSC70 (1:5000 dilution) was used for normalization of loading. D, E, Confocal images of P13 wild-type and Myoc-null optic nerves in longitudinal sections. Sections were stained with antibodies against MBP (1:500 dilution) or CNPase (1:500 dilution). Nuclei were stained with DAPI (blue). Scale bars: $10 \mu \mathrm{m}$.

In the mouse optic nerve, myocilin protein was detected starting from P6 and its level progressively increased between P6 and P25. However, myocilin level in the optic nerve of adult mice was $\sim 40 \%$ lower than at P25 (Fig. 1A,B). To analyze myocilin localization in the optic nerve, we stained longitudinal sections of 1-monthold optic nerve with antibodies against myocilin and GFAP, an astrocyte marker. Similar to its distribution in the adult rat optic nerve (Ohlmann et al., 2003), myocilin showed the most intensive staining in stellate-shaped cells and was partially colocalized with GFAP (Fig. 1D). Myocilin was also expressed in astrocytes isolated from the optic nerve of P7 mice and cultivated for $7 \mathrm{~d}$ (Fig. 1E). In cultured astrocytes, myocilin showed a typical perinuclear staining similar to its distribution in trabecular meshwork cells and optic nerve head human astrocytes (Lütjen-Drecoll et al., 1998, Clark et al., 2001).

We (Kwon et al., 2013a) and others (Ohlmann et al., 2003) have demonstrated that myocilin is expressed in the sciatic nerve where it localizes to Schwann cells and concentrates at the nodes of Ranvier. In the optic nerve, myocilin is not concentrated at nodes of Ranvier as shown by immunostaining of the longitudinal sections of the optic nerve with antibodies against myocilin and perinodal marker Caspr (Menegoz et al., 1997, Peles et al., 1997; Fig. 1C). Since Myoc-null mutation led to profound changes in myelination of the sciatic nerve and its structure

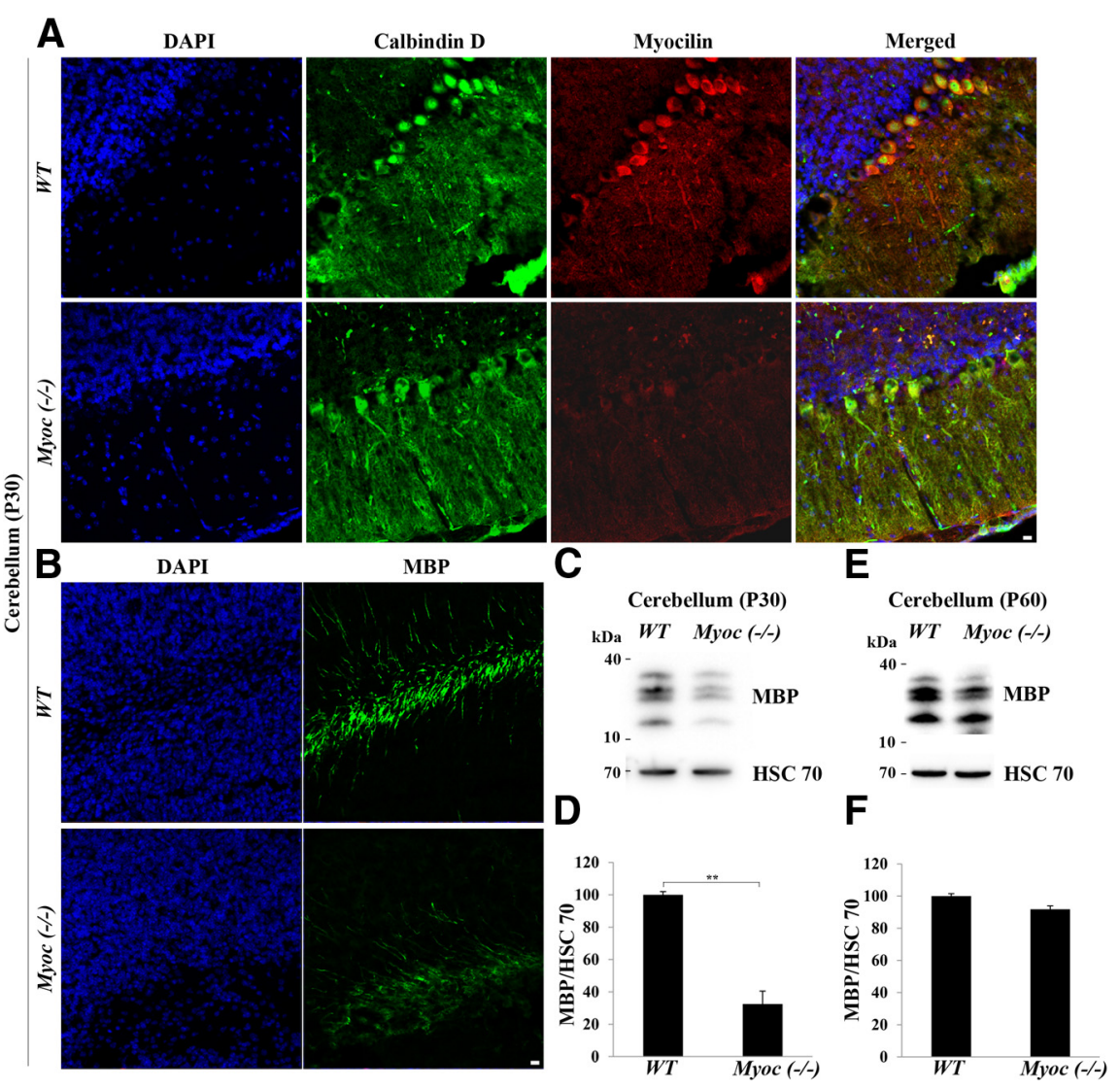

Figure 3. Reduced level of MBP in the cerebellum of P30 Myoc-null mice. A, Confocal images of wild-type (WT) and Myoc cerebellum. Sections were stained with antibodies against myocilin (red; 1:200 dilution and calbindin D, Purkinje cell marker, green; 1: 400 dilution). Nuclei were stained with DAPI (blue). Scale bar, $20 \mu \mathrm{m}$. B, Confocal images of wild-type and Myoc cerebellum. Sections were stained with antibodies against MBP (1:200 dilution). Nuclei were stained with DAPI (blue). Scale bar, $20 \mu \mathrm{m}$. C, $\boldsymbol{E}$, Western blot analysis of $\mathrm{P} 30(\boldsymbol{C})$ and P60 (E) cerebellum lysates of wild-type and Myoc-null mice using MBP antibodies (1:1000 dilution). Staining of the same blot with antibodies against HSC70 (1:5000 dilution) was used for normalization of loading. $\boldsymbol{D}, \boldsymbol{F}$, Quantification of four independent Western blot experiments as in $\boldsymbol{C}$ and $\boldsymbol{E}$, respectively. The levels of MBP in the cerebellum of wild-type mice were taken as $100 \%\left({ }^{* *} p<0.01\right)$. 

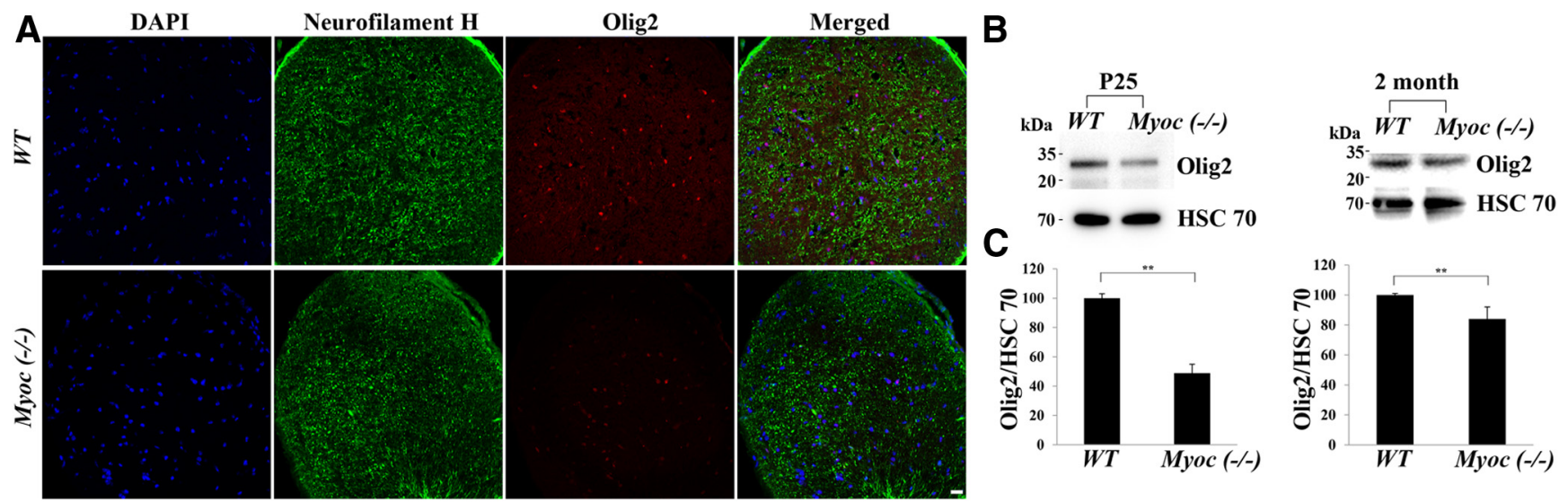

Figure 4. $\quad \boldsymbol{A}$, Confocal images of P25 wild-type (WT) and Myoc-null optic nerves in transverse sections. Sections were stained with antibodies against neurofilament $\mathrm{H}$ (green; 1:500 dilution) and 0lig2 (red; 1:200 dilution). Nuclei were stained with DAPI (blue). Scale bar, $20 \mu \mathrm{m}$. B. Western blot analysis of optic nerve lysates of P25 and 2-month-old wild-type and Myoc-null mice using 0lig2 antibodies (1: 500 dilution). Staining of the same blot with antibodies against HSC70 (1:5000 dilution) was used for normalization of loading. C, Quantification of three independent Western blot experiments as in $\boldsymbol{B}$. The levels of Olig2 in the optic nerve of wild-type mice were taken as $100 \%\left({ }^{* *} p<0.01\right)$.

(Kwon et al., 2013a), we investigated the effects of myocilin deletion on the optic nerve in greater detail.

\section{Differentiation of oligodendrocytes is delayed in Myoc-null mice}

Myoc deletion led to profound changes in the levels of several myelin-associated proteins and reduced the thickness of myelin sheaths in sciatic nerve (Kwon et al., 2013a). Therefore, we tested the levels of MBP, myelin proteolipid protein (PLP), and 2' $3^{\prime}$ cyclic nucleotide $3^{\prime}$-phosphodiesterase (CNPase), the major proteins of the CNS myelin sheath, and MPZ (P0), one of the major proteins of the PNS myelin sheath, in the optic nerve of 2-monthold Myoc-null and wild-type mice. The levels of MPZ and CNPase were significantly reduced, while the levels of MBP and PLP were moderately reduced in $M y o c$-null mice compared with wildtype littermates (Fig. 2A,B). Immunostaining of P13 optic nerve with antibodies against MBP and CNPase also showed a reduced immunofluorescence of the Myoc-null as compared with wildtype samples (Fig. $2 D, E$ ). In the sciatic nerve, a difference in the MBP levels between $M y o c$-null and wild-type mice was more pronounced at early postnatal stages than in adults (Kwon et al., 2013a). A similar pattern was observed in the optic nerve: P13P21 Myoc-null mice showed a more dramatic reduction in the levels of MBP compared with wild-type littermates than adult pairs (Fig. 2C). Moreover, age-dependent difference in the MBP levels between $M y o c$-null and wild-type littermates was also observed in cerebellum, another site of myocilin expression in the CNS. Staining of P30 brain section with antibodies against myocilin demonstrated that it was localized in Purkinje cells (Fig. 3A). Similar to previously published data (Golan et al., 2008), MBP was detected in the white matter tracts of the cerebellum at this age (Fig. $3 B$ ). The level of MBP was significantly reduced in the cerebellum of P30 Myoc-null mice as compared with wild-type littermates (Fig. 3B-D). The MBP level was only slightly reduced in the cerebellum of P60 Myoc-null mice as compared with wildtype, but this difference was not statistically significant (Fig. $3 E, F)$.

Transcription factor Olig2 is one of the major transcription factors in oligodendrocyte lineage specification during development and promotes oligodendrocyte differentiation (for review, seeMeijer et al., 2012). Western blotting and immunofluorescence analyses demonstrated that the levels of Olig2 were reduced in P25 and adult optic nerve of Myoc-null mice as compared with their wild-type littermates (Fig. 4). This difference was more pronounced in P25 than in 2-month-old mice. In the course of optic nerve development, oligodendrocyte precursor cells (OPCs) migrate from the optic chiasm to the optic nerve head. The migration process starts at embryonic day 17.5 and comes to completion around P28 (Pernet et al., 2008). Our previous data suggested that myocilin may stimulate trabecular meshwork and NIH3T3 cell migration (Kwon and Tomarev, 2011). Since delayed migration of oligodendrocytes could contribute to the observed reduction in the levels of myelin proteins at early postnatal days, we tested whether myocilin absence affects migration of OPCs. We tested postnatal stages because myocilin could be detected in the optic nerve only after P6 (Fig. 1A). Longitudinal section of wild-type and Myoc-null P8-P25 optic nerves was stained with antibodies against Olig2. Although the levels of Olig2 immunofluorescence were reduced in Myoc-null samples as compared with their wild-type littermates, the distribution of Olig2-positive cells was similar in both cases (Fig. 5). This indicates that migration of oligodendrocytes is not dramatically affected in the optic nerve of Myoc-null mice. Together, these results suggest that differentiation of oligodendrocytes may be delayed in vivo in the absence of myocilin.

\section{Hypomyelination of the optic nerve in Myoc-null mice}

The reduction in the levels of myelin-associated proteins implies possible defects in the myelination of the optic nerve in Myoc-null mice. Therefore, we analyzed effects of myocilin deficiency on the myelination of the optic nerve at P13 and at P60. Electron microscopy (EM) examination of the optic nerve showed that the thickness of myelin was reduced in Myoc-null mice compared with wild-type littermates (Fig. 6). For quantitative analysis of myelin thickness, we measured g-ratios of myelinated axons (inner axon diameter/total fiber diameter of myelinated axons) close to the optic nerve head. A significant increase in the average g-ratio was observed in the optic nerve of P13 Myoc-null mice compared with their wild-type littermates $(0.75 \pm 0.041$ vs $0.63 \pm 0.017$, respectively, $p<0.05$; Fig. $6 C)$. In contrast, the g-ratio only slightly changed in the optic nerve of P60 Myoc-null and wild-type mice $(0.72 \pm 0.014$ vs $0.68 \pm 0.017$, respectively; Fig. $6 F$ ). When such measurements were made close to the chiasm, results were very similar: $0.74 \pm 0.065$ versus $0.63 \pm 0.021$ at 


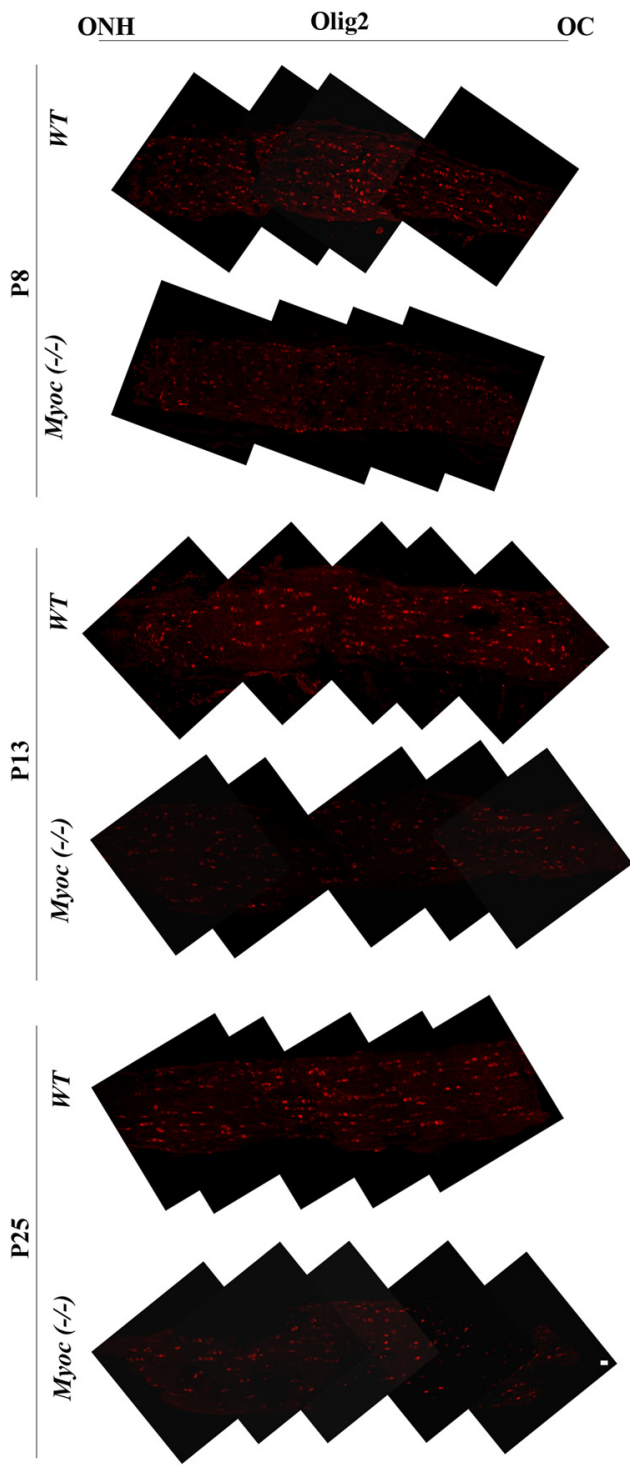

Figure 5. Effects of Myoc deletion on migration of OPCs in the optic nerve. Optic nerve longitudinal $10-\mu \mathrm{m}$-thick longitudinal sections were stained with antibodies against 0lig2 (1:200 dilution). OPCs migrated from the optic chiasm (OC) starting from embryonic day 17.5 in wild-type mice and stopped migrating in the optic nerve head (0NH) by P4 (Pernet et al., 2008). Scale bar, $20 \mu \mathrm{m}$.

$\mathrm{P} 13$ and $0.71 \pm 0.064$ versus $0.67 \pm 0.045$ at $\mathrm{P} 60$ for $M y o c$-null and wild-type samples. The differences in the g-ratio were more pronounced in axons of smaller diameter $(<3 \mu \mathrm{m})$. The ultrastructure and periodicity of compact myelin were similar in Myoc-null and control mice, suggesting that the reduced thickness of myelin reflects fewer myelin wraps. We concluded that the Myoc-null mutation leads to optic nerve myelination defects and these defects are more pronounced at P13 than at P60.

Loss of myocilin leads to abnormal visual activity in Myoc-null mice

To investigate whether defective myelination of the optic nerve in Myoc-null mice modifies functional integrity of visual pathways and the activity of the central visual system, we used fVEP recording. One-month-old mice were used in these experiments. fVEP response was delayed in $M y o c$-null mice compared with wildtype littermates indicating impaired salutatory conduction that could be attributed to defective myelination in the Myoc-null mice. At the same time, the amplitude of the response was increased in Myoc-null mice compared with wild-type littermates (Fig. 7). These results suggest that myocilin loss leads to abnormal visual function.

\section{Myocilin affects differentiation of immature OPCs in vitro}

The appearance of MBP, a mature oligodendrocyte marker, was delayed in Myoc-null mice (Fig. 2C), suggesting that myocilin secreted from optic nerve astrocytes may affect differentiation of oligodendrocytes in vivo. To test whether myocilin may affect differentiation of oligodendrocytes in vitro, immature oligodendrocytes from P5 mice were isolated and differentiated in culture for $8 \mathrm{~d}$ in the presence or absence of purified myocilin $(1 \mu \mathrm{g} / \mathrm{ml})$. The levels of MBP were increased in oligodendrocytes differentiating in the presence of myocilin compared with untreated oligodendrocytes as judged by Western blot analysis (Fig. 8A,B). Addition of antiserum against myocilin together with myocilin eliminated stimulating effects of myocilin. Addition of myocilin in the course of oligodendrocyte differentiation also led to a moderate increase in the level of MBP mRNA, as well as mRNA encoding myelin oligodendrocyte protein (Mog) and myelinassociated glycoprotein (Mag; Fig. 8C).

Stimulatory effects of myocilin on immature oligodendrocyte precursor differentiation suggested that myocilin may stimulate myelination in cocultures of DRG and immature oligodendrocytes. We cocultured isolated DRG and OPCs in the presence or absence of myocilin $(1 \mu \mathrm{g} / \mathrm{ml})$ for 3 weeks and then measured the length of myelin segments produced in cultures (Fig. 9A,B). Myocilin treatment produced $>3$-fold increase in the length of myelin segments as compared with untreated DRG cultures. Addition of antiserum against myocilin reduced stimulating effects of myocilin (Fig. 9A,B). The formation of myelin sheath after 4 weeks in culture was confirmed by EM. The thickness of myelin sheath was significantly increased in cocultures grown in the presence of myocilin (Fig. 9C). We concluded that myocilin stimulates differentiation of immature oligodendrocytes and myelination not only in vivo but also in vitro.

\section{Myocilin effects on oligodendrocyte differentiation occurs through its interaction with Lingo-1}

Extracellular molecules may regulate oligodendrocyte maturation by interaction with several receptors leading to the activation of corresponding signaling pathways. In the sciatic nerve, myocilin interacts with ErbB2/ErbB3 receptors and may affect myelination acting through this receptor family (Kwon et al., 2013a). We found that the levels of ErbB1 and ErbB2 in the optic nerve were very low and not detectable by Western blotting, while they were easily detectable in the sciatic nerve in the same conditions (data not shown). This is consistent with published data showing that in the postnatal rat optic nerve, ErbB1 is downregulated and is hardly detected after P21 (Liu and Neufeld, 2004). The level of ErbB4 mRNA was also extremely low in cultured rat optic nerve (Martínez et al., 2004). Additional experiments showed that, unlike in the sciatic nerve, ErbB2 and ErbB3 were not detected in the immunoprecipitates with myocilin antibodies (data not shown). On the basis of these observations we concluded that myocilin does not regulate oligodendrocyte differentiation through ErbB signaling.

Recently, we showed that another olfactomedin domaincontaining protein, olfactomedin 1, interacts with NgR1 and affects signaling through the Nogo receptor complex (Nakaya et al., 2012). To test possible binding of myocilin to $\mathrm{NgRl}$ and its coreceptor, Lingo-1, we used conditioned medium of COS-7 cells 

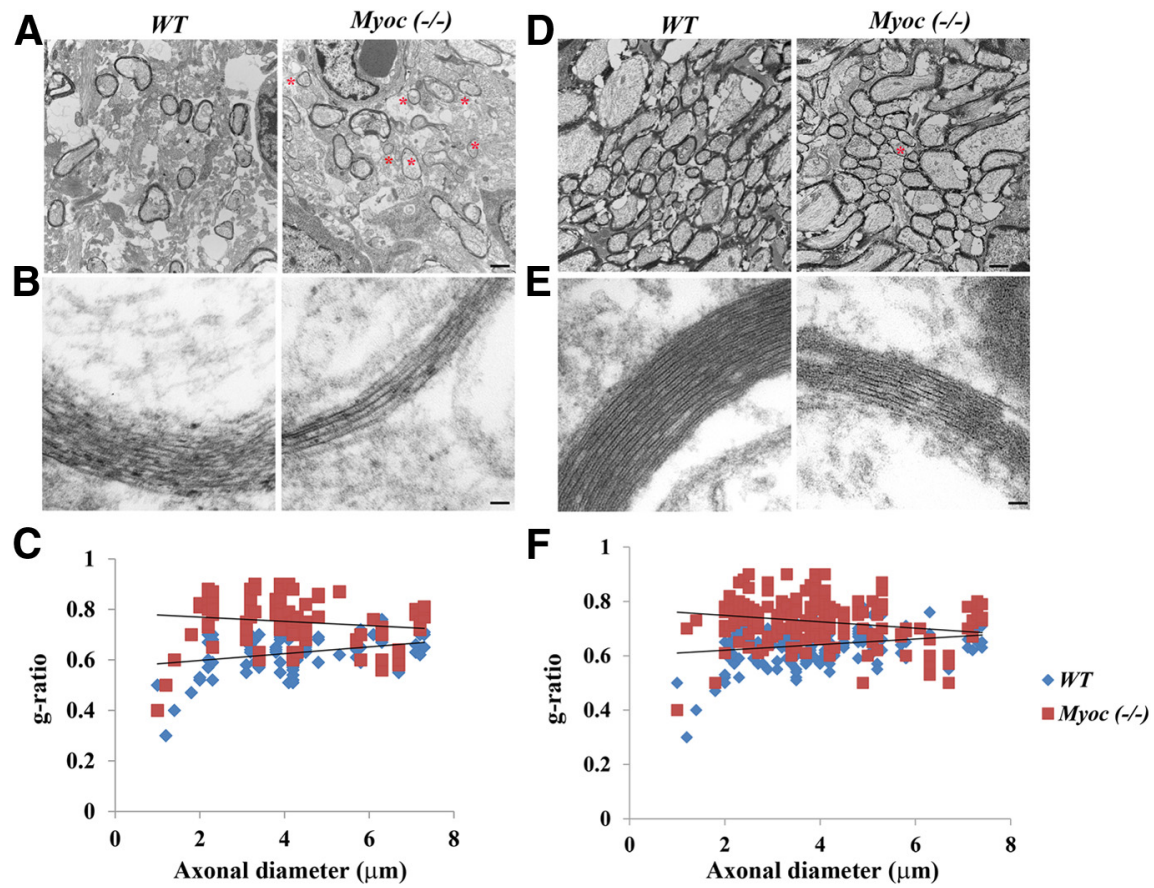

Figure 6. Myoc-null mice show defects in organization of optic nerves. Electron micrographs of the optic nerve cross sections of P13 $(\boldsymbol{A}, \boldsymbol{B})$ and P60 (D, E) wild-type (WT) and Myoc-null mice. Typical images are shown. Myoc-null mice showed a lower average axon diameter compared with wild-type animals. $A, D$, Asterisks mark unmyelinated axons or axon with a reduced myelin sheath. Five pairs of wild-type and Myoc-null mice were used in these experiments. Scale bars: $A, D, 2 \mu \mathrm{m} ; \boldsymbol{B}, \boldsymbol{E}, 100 \mathrm{~nm}$. $\boldsymbol{C}, \boldsymbol{F}, \mathrm{g}$-ratios (axon diameter/fiber diameter of myelinated axons) for the sciatic nerve of P13 $(\boldsymbol{C})$ and 2 -month-old $(\boldsymbol{F})$ wild-type and Myoc-null mice.
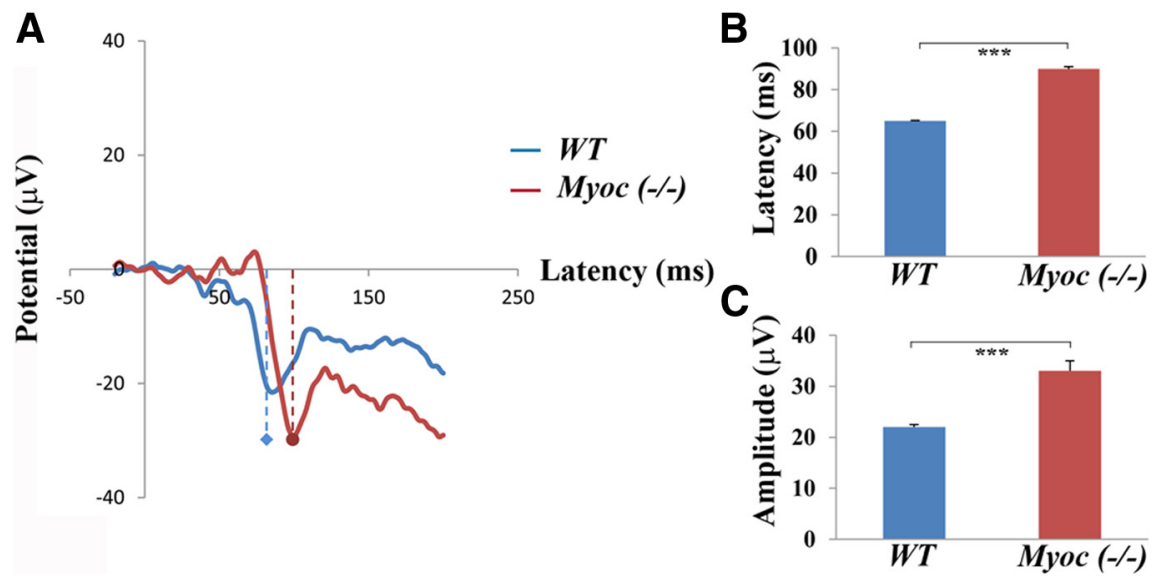

Figure 7. A, VEPs recorded in 1-month-old wild-type (WT) and Myoc-null mice. The data represent a typical recording. $\boldsymbol{B}, \boldsymbol{C}$ Quantification of data from five independent pairs of wild-type and Myoc-null littermates ( $\left.{ }^{* * *} p<0.005\right)$.

transiently transfected with a construct encoding full-length myocilin, N-terminal and C-terminal domains of myocilin fused to AP. Similar amounts of fusion proteins ( $~ 2 \mathrm{~nm}$; Fig. 10B) were added to COS-7 cells that were transfected with plasmids encoding the indicated cell-surface proteins. The activity of AP bound to cell membrane was visualized after $8 \mathrm{~h}$ of incubation as described in Materials and Methods (Fig. 10A). Both full-length myocilin and the N-terminal domain of myocilin but not C-terminal domain of myocilin demonstrated binding to the tested receptors indicating that the N-terminal domain of myocilin is critical for the interaction with Lingo-1 and NgR1. The affinities of myocilin for Lingo- 1 and NgR1 were estimated on the basis of binding of increased amounts of the myocilin-AP protein to COS-7 cells expressing corresponding constructs. The calcu- lated $K_{\mathrm{d}}$ were very similar for the constructs tested and were $\sim 24-26 \mathrm{~nm}$ (Fig. $10 C, D)$. Interaction of myocilin and Lingo- 1 in the optic nerve in vivo was confirmed by coimmunoprecipitation of these proteins from the optic nerve lysates (Fig. 10E,F).

It has been shown that Lingo-1 is a potent negative regulator of oligodendrocyte differentiation and axon regeneration ( $\mathrm{Mi}$ et al., 2004, 2005). To test whether stimulation of oligodendrocyte differentiation by myocilin treatment may occur through inhibition of Lingo-1 signaling, we infected OPCs differentiating into oligodendrocytes with Lingo-1 lentivirus in the presence or absence of myocilin. Lingo-1 lentivirus infection led to approximately twofold increase of Lingo-1 level in differentiating oligodendrocytes after $10 \mathrm{~d}$ in culture (Fig. 11A). This led to approximately twofold decrease in the MBP level (Fig. $11 A, B$ ). Addition of myocilin $3 \mathrm{~d}$ after Lingo-1 lentivirus infection and subsequent incubation for an additional $7 \mathrm{~d}$ restored the MBP level to the level exceeding the control one, but this level was lower than the MBP level in oligodendrocytes that were treated with myocilin without Lingo-1 lentivirus infection (Fig. $11 A, B)$. Immunostaining of oligodendrocyte cultures differentiating in different conditions confirmed Western blotting results: Lingo-1 infection reduced the level of MBP immunofluorescence, while treatment with myocilin restored the level of MBP fluorescence to the level exciding the control one (Fig. 11C). The soluble Lingo-1 ectodomain was shown to reverse inhibitory effects of full-lengthLingo- 1 on oligodendrocyte differentiation (Jepson et al., 2012). Indeed, addition of moderate concentrations of soluble Lingo-1 (0.2 $\mu \mathrm{g} / \mathrm{ml})$ increased the MBP level in the differentiating oligodendrocytes, while simultaneous addition of soluble Lingo-1 and myocilin produced stimulatory effect exceeding the stimulatory effects of myocilin or soluble Lingo-1 when they were added separately (Figs. $11 D, E, 8 A$ ). On the basis of these experiments we concluded that myocilin effects on oligodendrocyte differentiation are mediated by its interaction with the Lingo-1 receptor.

\section{Myocilin induces elongation of oligodendrocyte processes via RhoA-Fyn signaling}

Differentiation of oligodendrocytes in culture is accompanied by the growth of cell processes (Hardy and Reynolds, 1991, Pfeiffer et al., 1993). Addition of myocilin $(1 \mu \mathrm{g} / \mathrm{ml})$ to differentiating OPCs increased the length of their processes as compared with untreated differentiating OPCs, while the addition of antibodies against myocilin together with myocilin eliminated the stimulating effect of myocilin (Fig. 12A). To quantify stimulation effect of 
myocilin, we stained differentiated oligodendrocytes with antibodies against $\mathrm{O} 4$, an oligodendrocyte marker, and measured the length of the processes as described in Materials and Methods (Fig. $12 B, C)$. Quantification of these experiments demonstrated that addition of myocilin increased the process length by $45 \%$ after $8 \mathrm{~d}$ of differentiation in culture (Fig. 12C).

It has been demonstrated that stimulation of oligodendrocyte process elongation by blocking Lingo-1 functions may include suppression of RhoA-GTP (Mi et al., 2005). Similarly, addition of soluble Lingo-1, myocilin, or their combination decreased the levels of RhoA-GTP in differentiating oligodendrocytes (Fig. 13A$D)$. It has been shown that activity of RhoA-GTPase is regulated by Fyn kinase. Reduced levels of RhoA-GTPase and increased levels of phosphorylated Fyn (pFYN) are correlated with oligodendrocyte differentiation (Mi et al., 2005). Likewise, addition of myocilin to differentiating OPCs increased the levels of $\mathrm{pFYN}$ (Fig. 13E,F), while the level of pFYN was reduced in the optic nerve of Myoc-null mice as compared with their wild-type littermates (Fig. 13G,H). These data suggest that myocilin-induced elongation of oligodendrocyte processes may be mediated by activation of FYN and suppression of RhoA-GTPase.

\section{Discussion}

Axon myelination is critical for a rapid salutatory impulse conduction and protection against axonal damage in both the CNS and PNS of vertebrates. The correct timing of myelination is essential for the normal development of neurons. The multilayered myelin sheaths around largecaliber axons consist of spiral wraps of the plasma membrane of specialized glial cells, Schwann cells in the PNS, and oligodendrocytes in the CNS. Signals controlling myelination and the regulation of myelination differ between the CNS and PNS (Brinkmann et al., 2008, Taveggia et al., 2010). In the PNS, axon-derived factor neuregulin 1 ( Nrg1) is one of the key factors regulating myelination (Michailov et al., 2004, Taveggia et al., 2005). Nrg1 acts by activating a family of tyrosine kinase ErbBs with ErbB2-ErbB3 playing a critical role in the sciatic nerve (Birchmeier, 2009). However, the role of Nrg1 in myelination of the CNS remains controversial (Brinkmann et al., 2008). Other extracellular ligands and secreted molecules as well as intrinsic control of oligodendrocyte differentiation may play critical functions in the myelination of the CNS (Emery, 2010). Data reported here together with our published data (Kwon et al., 2013a)

A shown. Scale bar, $5 \mathrm{~nm}$.

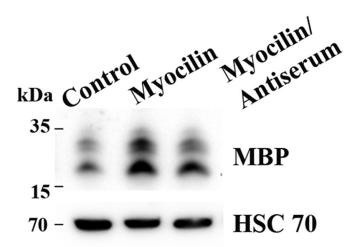

B 250
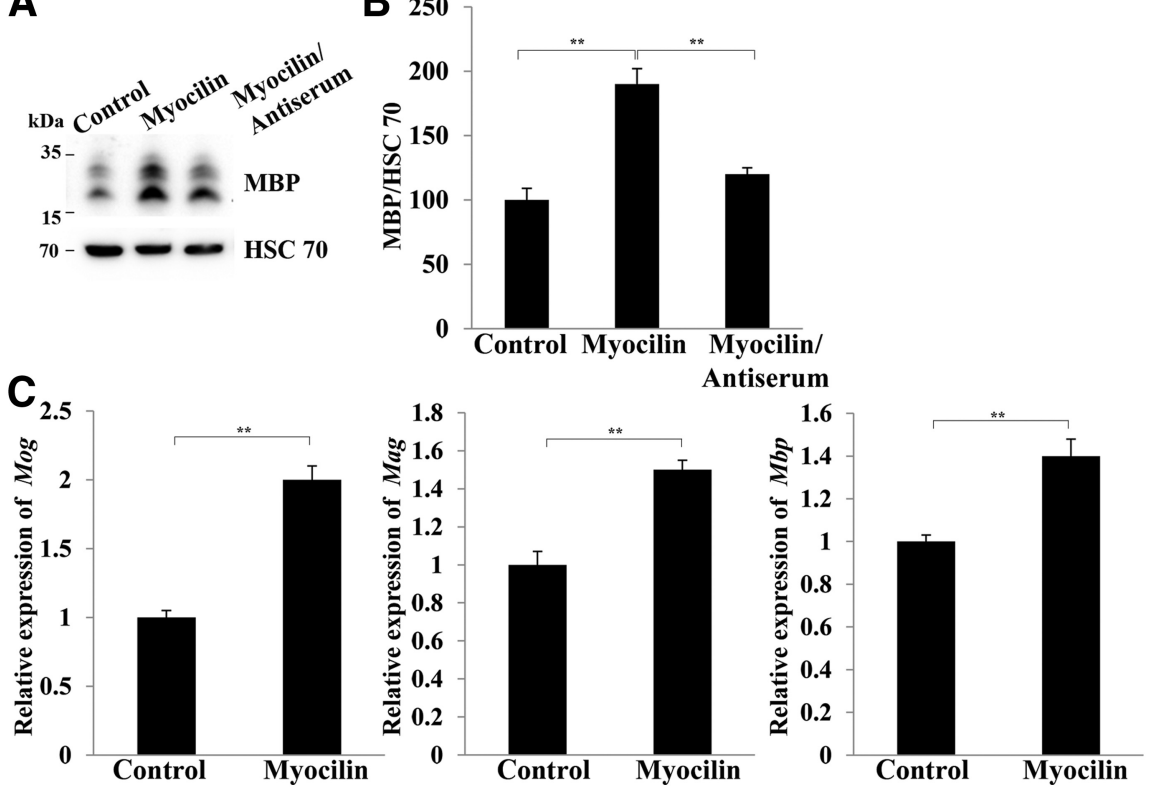

Figure 8. A, Western blot analysis of OPCs that were differentiated for $6 \mathrm{~d}$ in the presence $(1 \mu \mathrm{g} / \mathrm{ml})$ or absence of myocilin. Antiserum against myocilin was added together with myocilin to oligodendrocytes in Myocilin/antiserum lane. $\boldsymbol{B}$, Quantification of three independent Western blot experiments as in $\boldsymbol{A}$. The level of MBP in OPCs differentiating in the absence of myocilin was taken as $100 \%$ ( $\left.{ }^{* *} p<0.01\right)$. C, Relative levels of indicated mRNAs in oligodendrocytes differentiating in the absence or presence of myocilin $(1 \mu \mathrm{g} / \mathrm{ml})$ for $8 \mathrm{~d}$ as judged by qRT-PCR analysis. GAPDH mRNA was used for normalization. The mean level of expression of corresponding mRNAs in the absence of myocilin was taken as one arbitrary unit ( $\left.{ }^{* *} p<0.01\right)$.
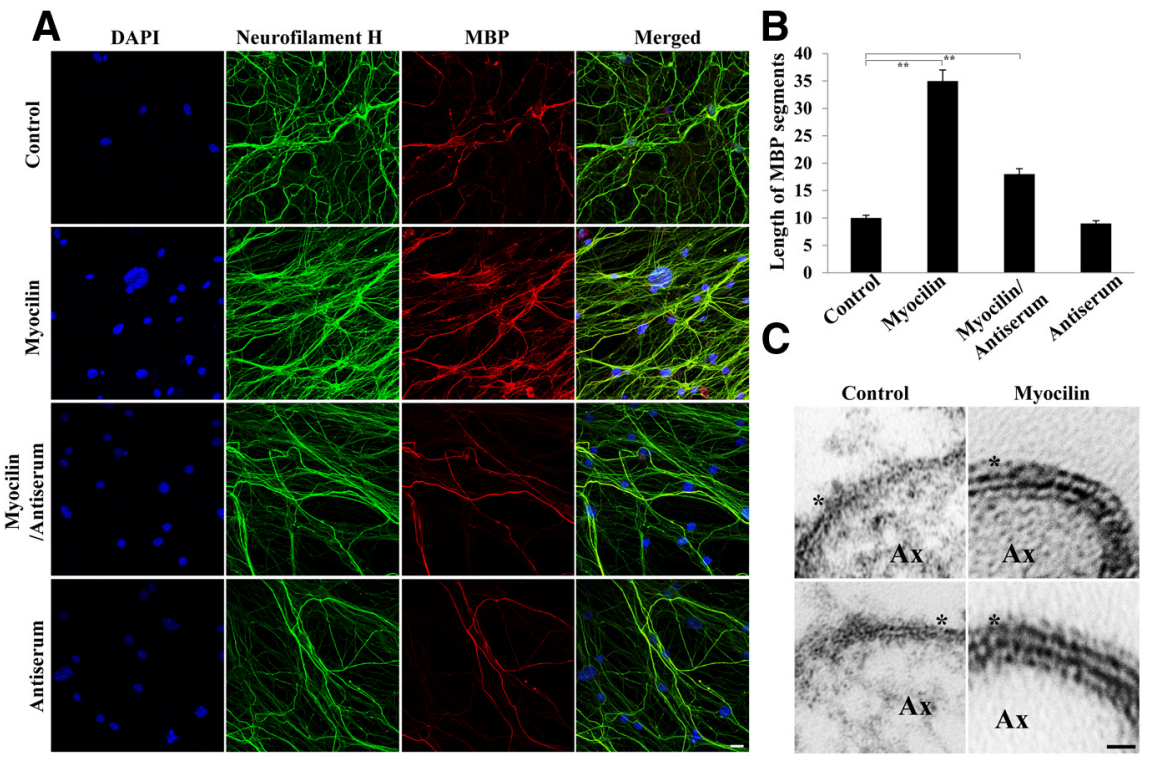

Figure 9. Myocilin stimulates oligodendrocyte-induced myelination in DRG cultures. $\boldsymbol{A}, \mathrm{DRG}$ were cocultured with oligodendrocytes in the presence $(1 \mu \mathrm{g} / \mathrm{ml})$ or absence of myocilin for 3 weeks and then stained with antibodies against neurofilament $\mathrm{H}$ (green; 1:500 dilution) and MBP (red; 1:200 dilution). The length of MBP-stained fragments was measured as described in Materials and Methods. Scale bar, $10 \mu \mathrm{m}$. B, Quantification of the results shown in $\boldsymbol{A}$. Length of MPB stained segments is shown in arbitrary units $\left({ }^{* *} p<0.01\right)$. C, EM analysis of DRG myelination by oligodendrocytes. DRG and oligodendrocytes were cocultured for 4 weeks in the absence or presence of myocilin ( $1 \mu \mathrm{g} / \mathrm{ml})$. The asterisk marks the myelin sheath. Ax, Axon. Typical images are

indicate that myocilin plays a role in myelination of both the CNS and PNS.

Myocilin has multiple functions in ocular and nonocular tissues and may act through different signaling pathways. Previously, we demonstrated that myocilin may act as a modulator of the Wnt signaling pathway and its overexpression in the eye angle 

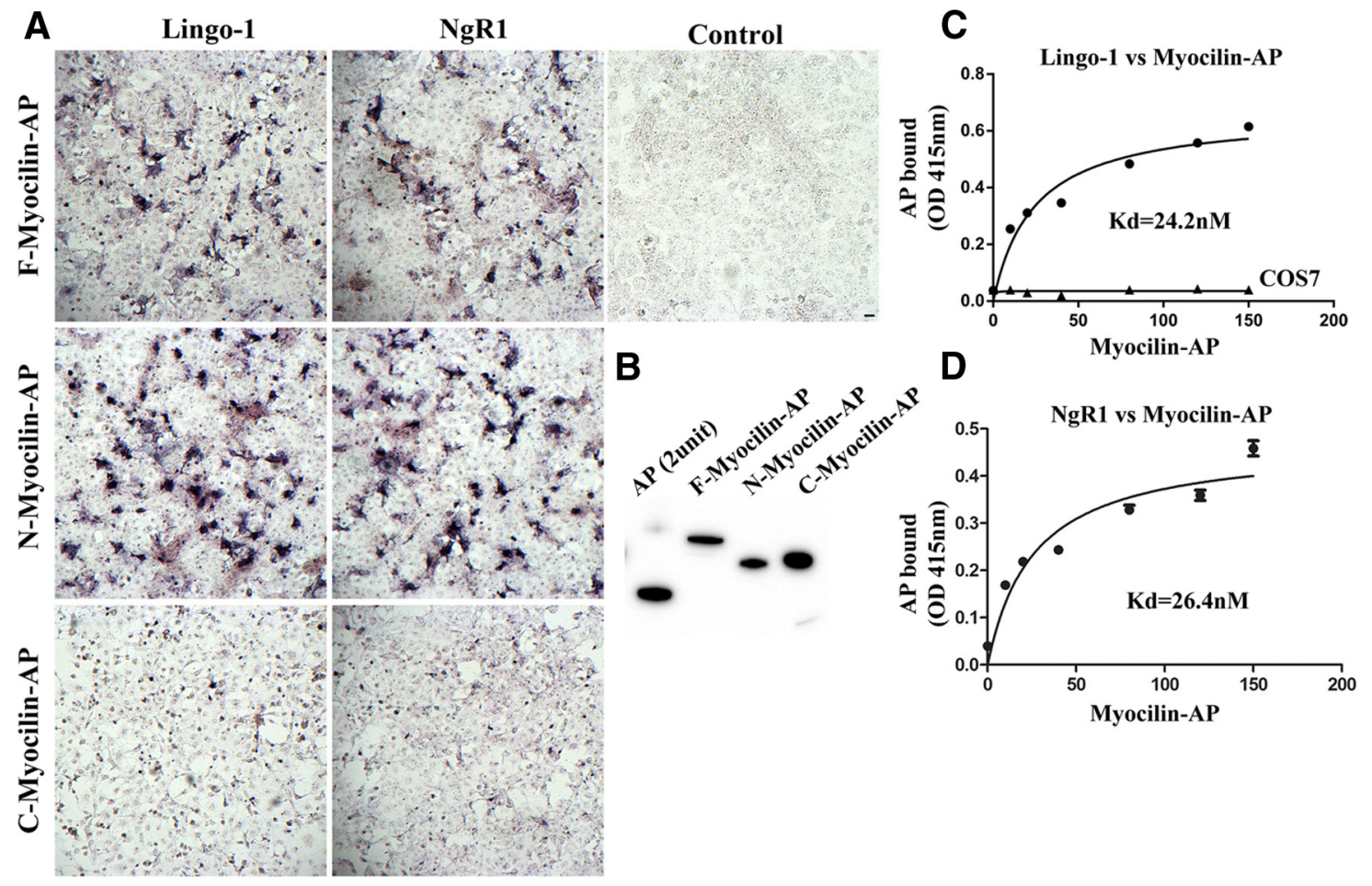

E

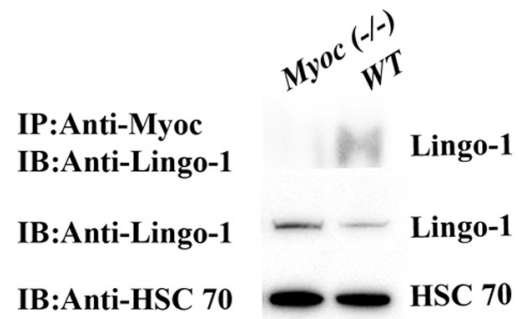

$\mathbf{F}$

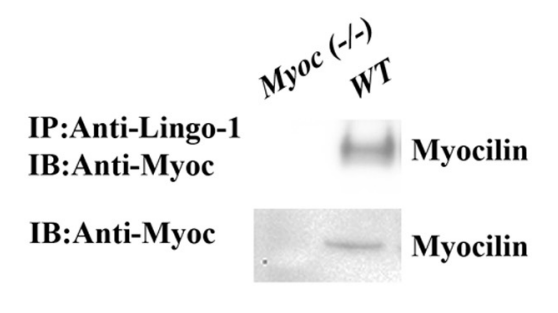

Figure 10. Secreted myocilin-AP binds to Lingo-1 and NgR1 on the surface of COS-7 cells. $A$, Myocilin-AP binds to Lingo-1, NgR1, and their combination on the surface of COS-7 cells. COS-7 cells transfected with receptor-expressing constructs indicated in each part. Two days later, cells were incubated with 2 nm myocilin-AP and stained for bound AP. In a control sample, COS-7 cells were transfected with the empty vector. Scale bar, $10 \mu \mathrm{m}$. B. Western blot analysis of the level of AP-fusion proteins added to COS-7 cells transfected with constructs shown in $\boldsymbol{A}$. Antiserum against AP was used in 1:1000 dilution. $\boldsymbol{C}, \boldsymbol{D}$, Binding of the increasing concentration of myocilin-AP to Lingo- $1(\boldsymbol{C})$ and $\mathrm{NgR} 1(\boldsymbol{D})$. These data were used for $K_{\mathrm{d}}$ calculation. $\boldsymbol{E}, \boldsymbol{F}$, Coimmunoprecipitation of myocilin with Lingo-1 from the extracts of optic nerve. Extracts were treated with antibodies against myocilin (1:1000 dilution) or Lingo-1 (1:1000 dilution), and protein complexes were immunoprecipitated using protein $\mathrm{G}$ beads, eluted from the beads, separated by SDS-PAGE, and then probed with antibodies against Lingo-1 or myocilin (1:1000). Bottom shows Western blot of lysates (10\% input) before immunoprecipitation.

tissues of transgenic mice stimulated accumulation of $\beta$-catenin in these tissues (Kwon et al., 2009). In skeletal muscle, myocilin is part of the dystrophin-associated protein complex. It interacts with $\alpha 1$-syntrophin, a cytoplasmic component of the dystrophinassociated protein complex. Overexpression of myocilin in transgenic mice leads to a redistribution of some proteins in the dystrophin-associated protein complex and to muscle size increase compared with those in wild-type littermates suggesting that myocilin is one of the regulators of muscle hypertrophy (Joe et al., 2012). Myocilin also stimulates osteogenic differentiation of mesenchymal stem cells, which was associated with activation of the p38, Erk1/2, and JNK MAP kinase signaling pathways and with upregulated expression of the osteogenic transcription factors Runx 2 and Dlx5. Cortical bone thickness and trabecular volume, as well as the expression level of osteopontin, a known factor of bone remodeling and osteoblast differentiation, were reduced dramatically in the femurs of Myoc-null mice compared with wild-type mice (Kwon et al., 2013a).
Our recent data demonstrated that myocilin is expressed in Schwann cells and preferentially concentrated at the nodes of Ranvier in the sciatic nerve (Kwon et al., 2013b). It is interesting to note that another olfactomedin domain-containing protein, gliomedin, has also been detected at the PNS nodes where it was concentrated in Schwann cell microvilli (Eshed et al., 2005). Myocilin colocalizes with gliomedin in the nodal region of sciatic nerves and interacts with gliomedin via the $\mathrm{N}$-terminal domain of myocilin that lacks the olfactomedin domain. We suggested that myocilin and gliomedin may perform complimentary functions in the PNS, though the effects of the Myoc-null mutation appeared to be more severe than for gliomedin-null mutation. In the sciatic nerve, myocilin affects myelination, is involved in the organization of the nodes, and may act through the ErbB signaling pathway. Here we demonstrate that myocilin is also involved in myelination of the optic nerve. However, there are remarkable differences in the mechanisms of myocilin action in myelination of PNS and CNS. Unlike the sciatic nerve, myocilin is not ex- 

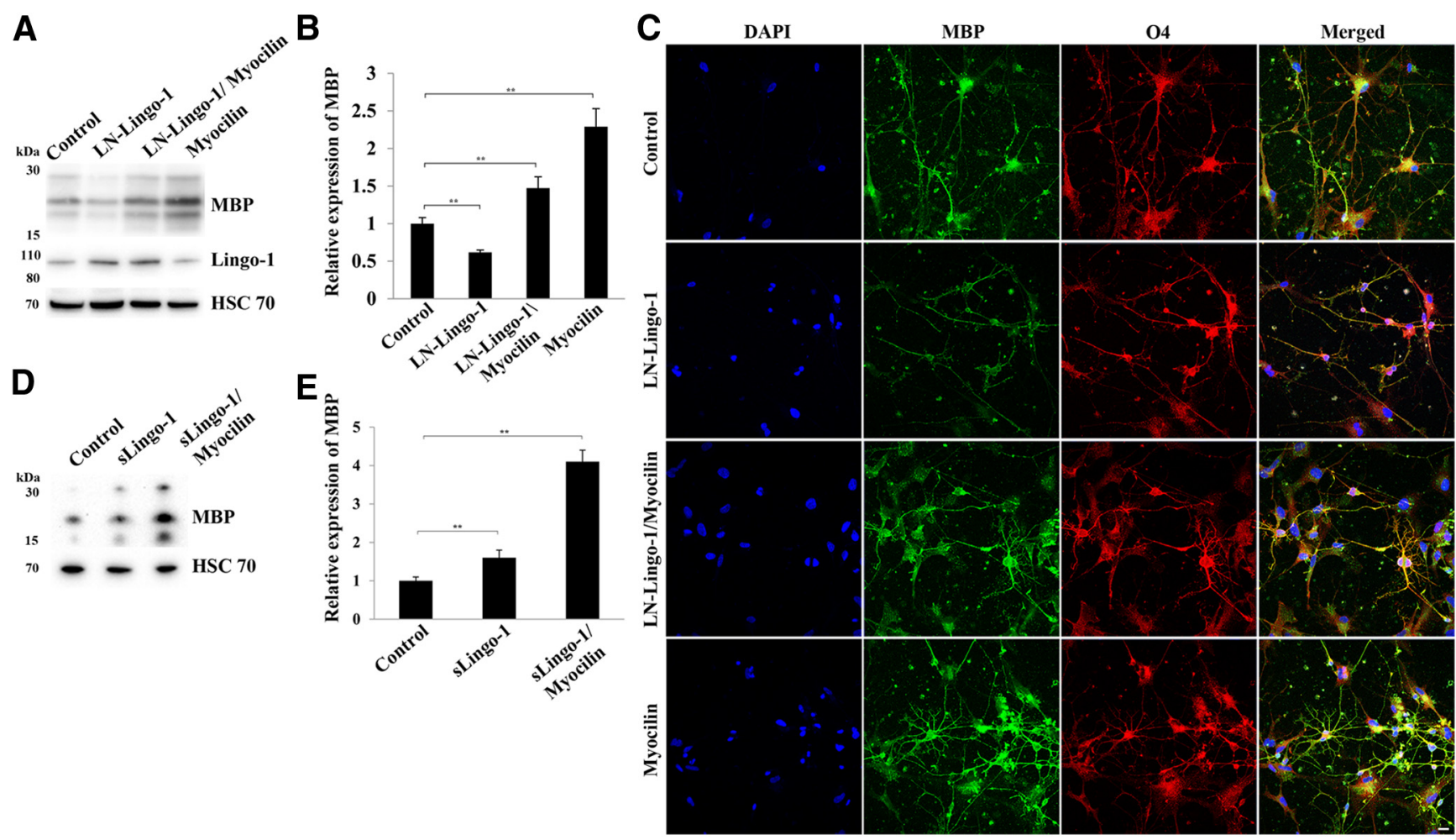

Figure 11. Myocilin affects oligodendrocyte differentiation through interaction with Lingo-1. A, Western blot analysis of oligodendrocytes differentiating after Lingo-1 lentivirus (LN-Lingo-1) infection in the absence or presence of myocilin for $10 \mathrm{~d}$. Myocilin $(1 \mu \mathrm{g} / \mathrm{ml})$ was added where shown $3 \mathrm{~d}$ after Lingo-1 lentivirus infection. Antibodies against MBP, Lingo-1, and HSC70 were used in 1:1000, 1:500, and 1:2000 dilutions, respectively. $\boldsymbol{B}$, Quantification of three Western blots as in $\boldsymbol{A}$. The MBP level in oligodendrocytes differentiating without addition of Lingo- 1 and myocilin was taken as one arbitrary unit $\left({ }^{* *} p<0.01\right)$. C, Confocal images of OPCs differentiating into oligodendrocytes after LN-Lingo-1 infection and myocilin treatment $(1 \mu \mathrm{g} / \mathrm{ml})$ for $10 \mathrm{~d}$ as in $\boldsymbol{A}$. Oligodendrocytes were stained with antibodies against MBP (1:500 dilution) and 04 (1:200 dilution). Nuclei were stained with DAPI (blue). Scale bar, $10 \mu \mathrm{m}$. D, Western blot analysis of oligodendrocytes differentiating in the absence or presence of soluble Lingo- 1 (sLingo- $1,0.2 \mu \mathrm{g} / \mathrm{ml}$ ) and myocilin $(0.5 \mu \mathrm{g} / \mathrm{ml}$ ) for $10 \mathrm{~d}$. Antibodies against MBP and HSC70 were used in 1:1000 and 1:2000 dilutions, respectively. $\boldsymbol{E}$, Quantification of three Western blots as in $\boldsymbol{D}\left({ }^{* *} p<0.01\right)$.
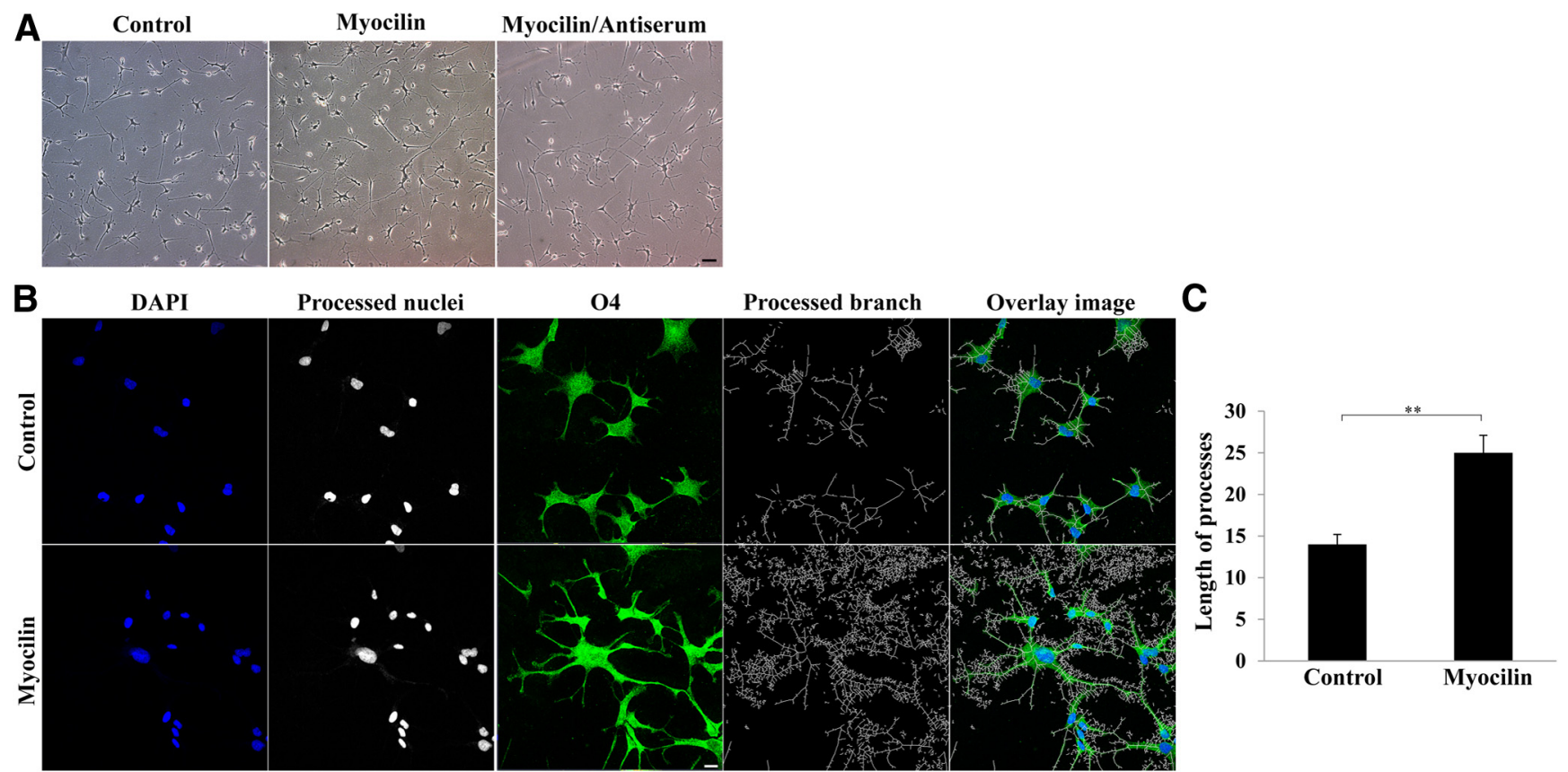

Figure 12. Myocilin stimulates elongation of oligodendrocyte processes. $A$, Differentiation of OPCs in vitro for $8 \mathrm{~d}$. Myocilin $(1 \mu \mathrm{g} / \mathrm{ml})$ or myocilin together with myocilin antiserum was added to oligodendrocytes after plating. Scale bar, $20 \mu \mathrm{m} . \boldsymbol{B}, 0 \mathrm{PC}$ s were grown as in $\boldsymbol{A}$ and then stained with antibodies against 04 (1:200 dilution). The length of oligodendrocyte processes was measured using the NeuriteTracer program as described in Materials and Methods. Scale bar, $10 \mu \mathrm{m}$. C, Process length (measured in arbitrarily units) of control and myocilin-treated oligodendrocyte precursor differentiating as in $\boldsymbol{B} .{ }^{* *} p<0.01$. 

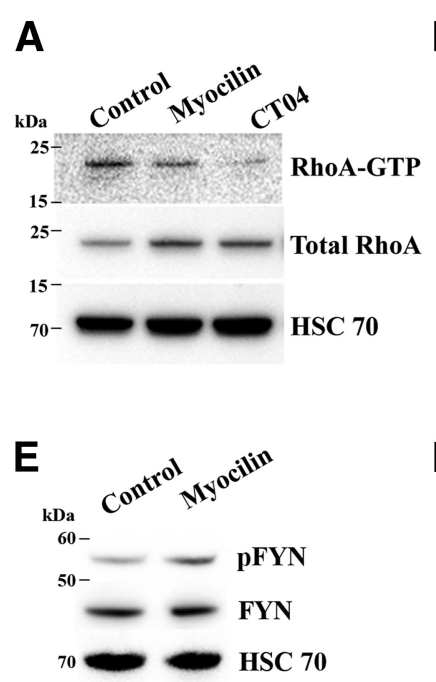
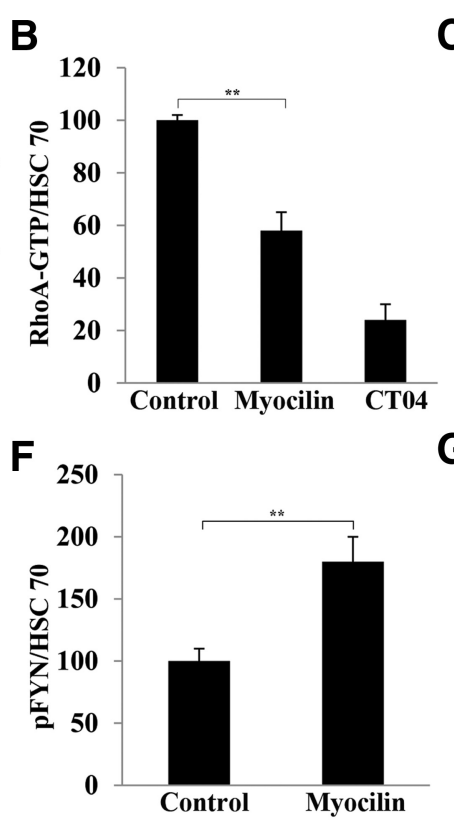

C

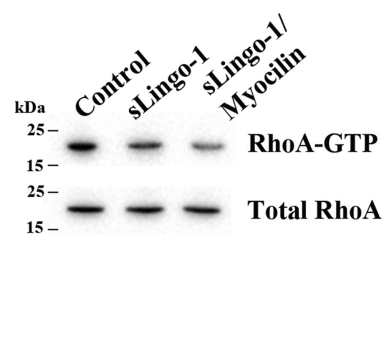

G

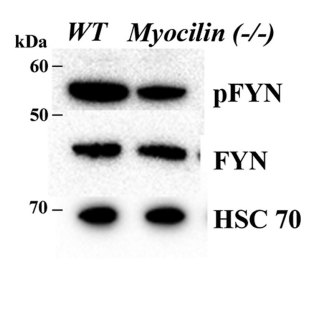

D

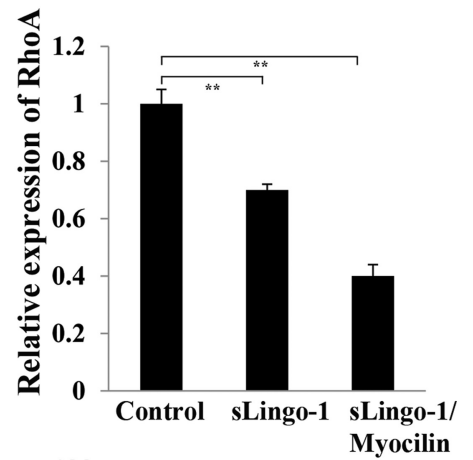

H

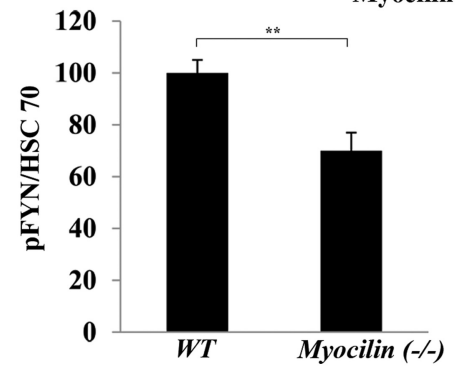

Figure 13. Myocilin effects on RhoA-GTPase and pFYN. A-D, RhoA-GTP levels in control oligodendrocytes and oligodendrocytes treated with soluble Lingo-1 (sLingo-1; $0.2 \mu \mathrm{g} / \mathrm{ml}$ ) and myocilin $(1 \mu \mathrm{g} / \mathrm{ml})$ for $8 \mathrm{~d}$. Rho inhibitor CT04 (1.0 $\mu \mathrm{g} / \mathrm{ml})$ was used for positive control in $\boldsymbol{A}$. HSC70 was used for normalization. Quantifications of three Western blots are shown in $\boldsymbol{B}$ and $\boldsymbol{D}$. $\boldsymbol{E}$, Western blot analysis of Fyn phosphorylation in oligodendrocyte treated with myocilin for $8 \mathrm{~d}$ as in $\boldsymbol{A}$. Antibodies against Fyn and phosphorylated Fyn used were used in 1:1000 and 1:500 dilution, respectively. $\boldsymbol{G}$, Fyn phosphorylation in the optic nerve of wild-type (WT) and Myoc-null mice (P30). $\boldsymbol{F}, \boldsymbol{H}$, Quantification of three independent Western blots as in $\boldsymbol{E}$ and $\boldsymbol{G}$. HSC70 was used for normalization.

pressed in myelinating cells (oligodendrocytes) of the optic nerve but in another type of glial cells, astrocytes. This conclusion is supported by data on transcriptosomes of astrocytes, neurons, and oligodendrocytes from developing and mature mouse forebrain (Cahoy et al., 2008). According to these data, myocilin is enriched in astrocytes as compared with oligodendrocytes and neurons.

Myocilin is secreted from astrocytes and affects differentiation of oligodendrocytes. This was observed both in vivo, when we compared wild-type and Myoc-null optic nerves, and in vitro, when we compared differentiation of OPCs in the presence and absence of myocilin. Moreover, in the optic nerve, myocilin action may occur through the NgR1/Lingo-1 receptor complex. Myocilin binds to both NgR1 and Lingo-1 as judged by AP binding assay, while related protein, Olfm1, binds only to $\mathrm{NgR} 1$ but not to Lingo- 1 in the same test (Nakaya et al., 2012). Lingo-1 is a multifunctional protein that is not only a negative regulator of oligodendrocyte differentiation but is also involved in neuronal survival and axon regeneration. Lingo- 1 is a coreceptor of $\mathrm{NgR} 1$ complex that modulates the activity of myelin inhibitors participation in the regulation of axon growth (Mi et al., 2004, Zhang et al., 2009). It has been shown that Lingo-1 inhibits oligodendrocyte terminal differentiation through intercellular interactions and is capable of a self-association in trans. It was also suggested that Lingo- 1 acts as both a ligand and a receptor and that a disruption of homophilic interaction could lead to an increase in myelination (Jepson et al., 2012). Myocilin may be considered as the first Lingo-1 ligand. We suggest that interaction of myocilin with Lingo-1 may inhibit self-association of Lingo- 1 and thus promote differentiation of oligodendrocytes and myelination.

Although myocilin may stimulate trabecular meshwork and NIH3T3 cell migration acting through the integrin-focal adhesion kinase (FAK)-serine/threonine kinase (AKT) signaling pathway (Kwon and Tomarev, 2011), myocilin deletion does not dramatically affect migration of optic nerve OPCs. Similarly, sin- gle knock-out of Nogo A or MAG induced a delay in differentiation of optic nerve oligodendrocytes but did not affect migration of OPCs (Pernet et al., 2008).

Myocilin interacts with ErbB2/3 receptors with the affinity similar to that for Lingo-1 (Kwon et al., 2013b). However, only Lingo-1 but not ErbB2/3 was detected in the immunoprecipitates after immunoprecipitation of optic nerve lysates with myocilin antibodies, reflecting the fact that Lingo-1 and NgR1 are more abundant in the optic nerve than ErbB receptors and may indicate that the NgR/Lingo- 1 receptor complex but not the ErbB2/3 complex is essential for myocilin action in the optic nerve. Myocilin interaction with the NgR/Lingo-1 complex led to a reduction of RhoA GTPase activation associated with an increase of the length of oligodendrocyte processes. Similarly, it has been shown that a reduction of Lingo-1 results in an increase of the length of oligodendrocyte processes, while overexpression of Lingo-1 has an opposite effect (Mi et al., 2005).

Adult Myoc-null mice did not show any obvious defects in the optic nerve head (Kim et al., 2001). However, myocilin absence led to a reduced myelination of the optic nerve in Myoc-null mice as compared with wild-type littermates and this reduction was more pronounced at early postnatal stages than in adult animals. Similar observations were also made in the sciatic nerve of $\mathrm{Myoc}$ null mice (Kwon et al., 2013a). We believe that differentiation of optic nerve oligodendrocytes is delayed in Myoc-null mice compared with their wild-type littermates. A delay in the differentiation of oligodendrocytes was also observed in the cerebellum of P30 Myoc-null mice as judged by the MBP level. The levels of MBP were comparable in the cerebellum of P60 Myoc-null and wild-type mice. A similar delay in the differentiation of oligodendrocytes in the cerebellum at early postnatal days with a recovery at later postnatal stages was described in Nogo A-null mice (Pernet et al., 2008). A delay in oligodendrocyte differentiation at early postnatal stages with subsequent recovery in adults was also reported in the optic nerve of semaphorin 6A-null mice (Bernard 
et al., 2012) and in some neurological disorders including a mouse model of autism (Pacey et al., 2013). Reduced myelination in $M y o c$-null mice was accompanied by a modified visual function: a delayed fVEP response and the increased amplitude of the response (Fig. 7). The delay of fVEP was not surprising since it has been shown that the latency of the fVEP reflects the amount of demyelination in the visual pathway (You et al., 2011). The amplitude of fVEP usually correlates with axonal damage and its increase in $M y o c$-null mice compared with wild-type littermates was somewhat unexpected. However, it was shown that the correlation between axonal damage and amplitude was weaker than that between demyelination and latency and it was suggested that the function of the lost axons may be partially compensated in the visual system at the cortical level (You et al., 2011).

In conclusion, we have identified myocilin as a novel positive regulator of oligodendrocyte differentiation in the optic nerve. In the absence of myocilin, oligodendrocyte differentiation is delayed in vivo. Although addition of purified myocilin stimulated oligodendrocyte differentiation in vitro, further studies are necessary to elucidate whether similar effects could be observed in vivo. Moreover, interaction of myocilin with the NgR1/Lingo-1 complex opens a possibility that myocilin may be involved in the regulation of axon growth and regeneration.

\section{References}

Adam MF, Belmouden A, Binisti P, Brézin AP, Valtot F, Béchetoille A, Dascotte JC, Copin B, Gomez L, Chaventré A, Bach JF, Garchon HJ (1997) Recurrent mutations in a single exon encoding the evolutionarily conserved olfactomedin-homology domain of TIGR in familial open-angle glaucoma. Hum Mol Genet 6:2091-2097. CrossRef Medline

Bernard F, Moreau-Fauvarque C, Heitz-Marchaland C, Zagar Y, Dumas L, Fouquet S, Lee X, Shao Z, Mi S, Chédotal A (2012) Role of transmembrane semaphorin Sema6A in oligodendrocyte differentiation and myelination. Glia 60:1590-1604. CrossRef Medline

Birchmeier C (2009) ErbB receptors and the development of the nervous system. Exp Cell Res 315:611-618. CrossRef Medline

Brinkmann BG, Agarwal A, Sereda MW, Garratt AN, Müller T, Wende H, Stassart RM, Nawaz S, Humml C, Velanac V, Radyushkin K, Goebbels S, Fischer TM, Franklin RJ, Lai C, Ehrenreich H, Birchmeier C, Schwab MH, Nave KA (2008) Neuregulin-1/ErbB signaling serves distinct functions in myelination of the peripheral and central nervous system. Neuron 59:581-595. CrossRef Medline

Cahoy JD, Emery B, Kaushal A, Foo LC, Zamanian JL, Christopherson KS, Xing Y, Lubischer JL, Krieg PA, Krupenko SA, Thompson WJ, Barres BA (2008) A transcriptome database for astrocytes, neurons, and oligodendrocytes: a new resource for understanding brain development and function. J Neurosci 28:264-278. CrossRef Medline

Clark AF, Kawase K, English-Wright S, Lane D, Steely HT, Yamamoto T, Kitazawa Y, Kwon YH, Fingert JH, Swiderski RE, Mullins RF, Hageman GS, Alward WL, Sheffield VC, Stone EM (2001) Expression of the glaucoma gene myocilin (MYOC) in the human optic nerve head. FASEB J 15:1251-1253. Medline

Emery B (2010) Regulation of oligodendrocyte differentiation and myelination. Science 330:779-782. CrossRef Medline

Eshed Y, Feinberg K, Poliak S, Sabanay H, Sarig-Nadir O, Spiegel I, Bermingham JR Jr, Peles E (2005) Gliomedin mediates Schwann cell-axon interaction and the molecular assembly of the nodes of Ranvier. Neuron 47: 215-229. CrossRef Medline

Golan N, Adamsky K, Kartvelishvily E, Brockschnieder D, Möbius W, Spiegel I, Roth AD, Thomson CE, Rechavi G, Peles E (2008) Identification of Tmem10/Opalin as an oligodendrocyte enriched gene using expression profiling combined with genetic cell ablation. Glia 56:1176-1186. CrossRef Medline

Goto Y, Furuta A, Tobimatsu S (2001) Magnesium deficiency differentially affects the retina and visual cortex of intact rats. J Nutr 131:2378-2381. Medline

Hardy R, Reynolds R (1991) Proliferation and differentiation potential of rat forebrain oligodendroglial progenitors both in vitro and in vivo. Development 111:1061-1080. Medline
Jepson S, Vought B, Gross CH, Gan L, Austen D, Frantz JD, Zwahlen J, Lowe D, Markland W, Krauss R (2012) LINGO-1, a transmembrane signaling protein, inhibits oligodendrocyte differentiation and myelination through intercellular self-interactions. J Biol Chem 287:22184-22195. CrossRef Medline

Joe MK, Tomarev SI (2010) Expression of myocilin mutants sensitizes cells to oxidative stress-induced apoptosis. Implication for glaucoma pathogenesis. Am J Pathol 176:2880-2890. CrossRef Medline

Joe MK, Sohn S, Hur W, Moon Y, Choi YR, Kee C (2003) Accumulation of mutant myocilins in ER leads to ER stress and potential cytotoxicity in human trabecular meshwork cells. Biochem Biophys Res Commun 312: 592-600. CrossRef Medline

Joe MK, Kee C, Tomarev SI (2012) Myocilin interacts with syntrophins and is member of dystrophin-associated protein complex. J Biol Chem 287: 13216-13227. CrossRef Medline

Karali A, Russell P, Stefani FH, Tamm ER (2000) Localization of myocilin/ trabecular meshwork-inducible glucocorticoid response protein in the human eye. Invest Ophthalmol Vis Sci 41:729-740. Medline

Kim BS, Savinova OV, Reedy MV, Martin J, Lun Y, Gan L, Smith RS, Tomarev SI, John SW, Johnson RL (2001) Targeted disruption of the Myocilin gene (Myoc) suggests that human glaucoma-causing mutations are gain of function. Mol Cell Biol 21:7707-7713. CrossRef Medline

Kwon HS, Tomarev SI (2011) Myocilin, a glaucoma-associated protein, promotes cell migration through activation of integrin-focal adhesion kinase-serine/threonine kinase signaling pathway. J Cell Physiol 226:33923402. CrossRef Medline

Kwon HS, Lee HS, Ji Y, Rubin JS, Tomarev SI (2009) Myocilin is a modulator of Wnt signaling. Mol Cell Biol 29:2139-2154. CrossRef Medline

Kwon HS, Johnson TV, Joe MK, Abu-Asab M, Zhang J, Chan CC, Tomarev SI (2013a) Myocilin mediates myelination in the peripheral nervous system through ErbB2/3 signaling. J Biol Chem 288:26357-26371. CrossRef Medline

Kwon HS, Johnson TV, Tomarev SI (2013b) Myocilin stimulates osteogenic differentiation of mesenchymal stem cells through MAPK signaling. J Biol Chem 288:16882-16894. CrossRef Medline

Liu B, Neufeld AH (2004) Activation of epidermal growth factor receptors directs astrocytes to organize in a network surrounding axons in the developing rat optic nerve. Dev Biol 273:297-307. CrossRef Medline

Lütjen-Drecoll E, May CA, Polansky JR, Johnson DH, Bloemendal H, Nguyen TD (1998) Localization of the stress proteins alpha B-crystallin and trabecular meshwork inducible glucocorticoid response protein in normal and glaucomatous trabecular meshwork. Invest Ophthalmol Vis Sci 39: 517-525. Medline

Malyukova I, Lee HS, Fariss RN, Tomarev SI (2006) Mutated mouse and human myocilins have similar properties and do not block general secretory pathway. Invest Ophthalmol Vis Sci 47:206-212. CrossRef Medline

Martínez JC, Malavé C, Bosch I, Castillo C, Núñez J, Villegas GM, Villegas R (2004) A real-time quantitative PCR comparative study between rat optic and sciatic nerves: determination of neuregulin-1 mRNA levels. Brain Res Mol Brain Res 130:49-60. CrossRef Medline

Meijer DH, Kane MF, Mehta S, Liu H, Harrington E, Taylor CM, Stiles CD, Rowitch DH (2012) Separated at birth? The functional and molecular divergence of OLIG1 and OLIG2. Nat Rev Neurosci 13:819-831. CrossRef Medline

Menegoz M, Gaspar P, Le Bert M, Galvez T, Burgaya F, Palfrey C, Ezan P, Arnos F, Girault JA (1997) Paranodin, a glycoprotein of neuronal paranodal membranes. Neuron 19:319-331. CrossRef Medline

Mi S, Lee X, Shao Z, Thill G, Ji B, Relton J, Levesque M, Allaire N, Perrin S, Sands B, Crowell T, Cate RL, McCoy JM, Pepinsky RB (2004) LINGO-1 is a component of the Nogo-66 receptor/p75 signaling complex. Nat Neurosci 7:221-228. CrossRef Medline

Mi S, Miller RH, Lee X, Scott ML, Shulag-Morskaya S, Shao Z, Chang J, Thill G, Levesque M, Zhang M, Hession C, Sah D, Trapp B, He Z, Jung V, McCoy JM, Pepinsky RB (2005) LINGO-1 negatively regulates myelination by oligodendrocytes. Nat Neurosci 8:745-751. CrossRef Medline

Michailov GV, Sereda MW, Brinkmann BG, Fischer TM, Haug B, Birchmeier C, Role L, Lai C, Schwab MH, Nave KA (2004) Axonal neuregulin-1 regulates myelin sheath thickness. Science 304:700-703. CrossRef Medline

Nakaya N, Sultana A, Lee HS, Tomarev SI (2012) Olfactomedin 1 interacts with the nogo a receptor complex to regulate axon growth. J Biol Chem 287:37171-37184. CrossRef Medline 
Noda S, Mashima Y, Obazawa M, Kubota R, Oguchi Y, Kudoh J, Minoshima S, Shimizu N (2000) Myocilin expression in the astrocytes of the optic nerve head. Biochem Biophys Res Commun 276:1129-1135. CrossRef Medline

Ohlmann A, Goldwich A, Flügel-Koch C, Fuchs AV, Schwager K, Tamm ER (2003) Secreted glycoprotein myocilin is a component of the myelin sheath in peripheral nerves. Glia 43:128-140. CrossRef Medline

Ortego J, Escribano J, Coca-Prados M (1997) Cloning and characterization of subtracted cDNAs from a human ciliary body library encoding TIGR, a protein involved in juvenile open angle glaucoma with homology to myosin and olfactomedin. FEBS Lett 413:349-353. CrossRef Medline

Pacey LK, Xuan IC, Guan S, Sussman D, Henkelman RM, Chen Y, Thomsen C, Hampson DR (2013) Delayed myelination in a mouse model of fragile X syndrome. Hum Mol Genet 22:3920-3930. CrossRef Medline

Peles E, Nativ M, Lustig M, Grumet M, Schilling J, Martinez R, Plowman GD, Schlessinger J (1997) Identification of a novel contactin-associated transmembrane receptor with multiple domains implicated in proteinprotein interactions. EMBO J 16:978-988. CrossRef Medline

Pernet V, Joly S, Christ F, Dimou L, Schwab ME (2008) Nogo-A and myelinassociated glycoprotein differently regulate oligodendrocyte maturation and myelin formation. J Neurosci 28:7435-7444. CrossRef Medline

Pfeiffer SE, Warrington AE, Bansal R (1993) The oligodendrocyte and its many cellular processes. Trends Cell Biol 3:191-197. CrossRef Medline

Poliak S, Salomon D, Elhanany H, Sabanay H, Kiernan B, Pevny L, Stewart CL, Xu X, Chiu SY, Shrager P, Furley AJ, Peles E (2003) Juxtaparanodal clustering of Shaker-like $\mathrm{K}+$ channels in myelinated axons depends on Caspr2 and TAG-1. J Cell Biol 162:1149-1160. CrossRef Medline

Ren XD, Kiosses WB, Schwartz MA (1999) Regulation of the small GTPbinding protein Rho by cell adhesion and the cytoskeleton. EMBO J 18: 578-585. CrossRef Medline
Ricard CS, Agapova OA, Salvador-Silva M, Kaufman PL, Hernandez MR (2001) Expression of myocilin/TIGR in normal and glaucomatous primate optic nerves. Exp Eye Res 73:433-447. CrossRef Medline

Stone EM, Fingert JH, Alward WL, Nguyen TD, Polansky JR, Sunden SL, Nishimura D, Clark AF, Nystuen A, Nichols BE, Mackey DA, Ritch R, Kalenak JW, Craven ER, Sheffield VC (1997) Identification of a gene that causes primary open angle glaucoma. Science 275:668-670. CrossRef Medline

Taveggia C, Zanazzi G, Petrylak A, Yano H, Rosenbluth J, Einheber S, Xu X, Esper RM, Loeb JA, Shrager P, Chao MV, Falls DL, Role L, Salzer JL (2005) Neuregulin-1 type III determines the ensheathment fate of axons. Neuron 47:681-694. CrossRef Medline

Taveggia C, Feltri ML, Wrabetz L (2010) Signals to promote myelin formation and repair. Nat Rev Neurol 6:276-287. CrossRef Medline

Tomarev SI, Wistow G, Raymond V, Dubois S, Malyukova I (2003) Gene expression profile of the human trabecular meshwork: NEIBank sequence tag analysis. Invest Ophthalmol Vis Sci 44:2588-2596. CrossRef Medline

You Y, Klistorner A, Thie J, Graham SL (2011) Latency delay of visual evoked potential is a real measurement of demyelination in a rat model of optic neuritis. Invest Ophthalmol Vis Sci 52:6911-6918. CrossRef Medline

Zhang Z, Xu X, Zhang Y, Zhou J, Yu Z, He C (2009) LINGO-1 interacts with WNK1 to regulate nogo-induced inhibition of neurite extension. J Biol Chem 284:15717-15728. CrossRef Medline

Zode GS, Kuehn MH, Nishimura DY, Searby CC, Mohan K, Grozdanic SD, Bugge K, Anderson MG, Clark AF, Stone EM, Sheffield VC (2011) Reduction of ER stress via a chemical chaperone prevents disease phenotypes in a mouse model of primary open angle glaucoma. J Clin Invest 121:3542-3553. CrossRef Medline 